\title{
The effect of doubled CO2 and model basic state biases on the monsoon-ENSO system. II: Changing ENSO regimes
}

Article

Published Version

Turner, A.G., Inness, P.M. and Slingo, J.M. (2007) The effect of doubled $\mathrm{CO} 2$ and model basic state biases on the monsoon-ENSO system. II: Changing ENSO regimes. Quarterly Journal of the Royal Meteorological Society, 133. pp. 1159-1173. ISSN 1477-870X doi: https://doi.org/10.1002/qj.83 Available at https://centaur.reading.ac.uk/858/

It is advisable to refer to the publisher's version if you intend to cite from the work. See Guidance on citing.

Published version at: http://dx.doi.org/doi:10.1002/qj.83

To link to this article DOI: http://dx.doi.org/10.1002/qj.83

Publisher: Royal Meteorological Society

All outputs in CentAUR are protected by Intellectual Property Rights law, including copyright law. Copyright and IPR is retained by the creators or other copyright holders. Terms and conditions for use of this material are defined in the End User Agreement.

www.reading.ac.uk/centaur 
Central Archive at the University of Reading

Reading's research outputs online 


\title{
The effect of doubled $\mathrm{CO}_{2}$ and model basic state biases on the monsoon-ENSO system. II: Changing ENSO regimes
}

\author{
A. G. Turner,* P. M. Inness and J. M. Slingo \\ Walker Institute, University of Reading, UK
}

\begin{abstract}
Integrations of a fully-coupled climate model with and without flux adjustments in the equatorial oceans are performed under $2 \times \mathrm{CO}_{2}$ conditions to explore in more detail the impact of increased greenhouse gas forcing on the monsoon-ENSO system. When flux adjustments are used to correct some systematic model biases, ENSO behaviour in the modelled future climate features distinct irregular and periodic (biennial) regimes. Comparison with the observed record yields some consistency with ENSO modes primarily based on air-sea interaction and those dependent on basinwide ocean wave dynamics. Simple theory is also used to draw analogies between the regimes and irregular (stochastically forced) and self-excited oscillations respectively. Periodic behaviour is also found in the Asian-Australian monsoon system, part of an overall biennial tendency of the model under these conditions related to strong monsoon forcing and increased coupling between the Indian and Pacific Oceans. The tropospheric biennial oscillation (TBO) thus serves as a useful descriptor for the coupled monsoon-ENSO system in this case. The presence of obvious regime changes in the monsoon-ENSO system on interdecadal timescales, when using flux adjustments, suggests there may be greater uncertainty in projections of future climate, although further modelling studies are required to confirm the realism and cause of such changes. Copyright $($ ) 2007 Royal Meteorological Society
\end{abstract}

KEY WORDS climatic shifts; interdecadal variability; El Niño; tropospheric biennial oscillation

Received 11 August 2006; Revised 22 January 2007; Accepted 12 March 2007

\section{Introduction}

Climate change will have uncertain socio-economic impacts on the agrarian societies of Southeast Asia through their dependence on the rainfall associated with the Asian-Australian monsoon system. The uncertainty in these predictions of the future monsoon climate is heightened by systematic model bias. Fully-coupled climate models possessing different systematic biases will present a different response to increased greenhouse gas forcing (e.g. Meehl et al., 2000). Part I of this study (Turner et al., 2007, hereafter TIS07) has shown that partial flux corrections may be used to make some assessment of the impact of systematic model bias on future climate change projections. Indeed TIS07 found that flux adjustments increased the response of the monsoon-ENSO system to increased greenhouse gas forcing. These results include an increase in the seasonal mean monsoon precipitation and its interannual variability, an increase in ENSO variability, and a robust teleconnection between it and the monsoon. Several issues remain outstanding, however, including a shift in ENSO frequency and the presence of marked climatic regimes.

Figure 1 shows the Niño- 3 region $\left(5^{\circ} \mathrm{N}-5^{\circ} \mathrm{S}, 150\right.$ $90^{\circ} \mathrm{W}$ ) anomaly index for the integration of the Unified

\footnotetext{
* Correspondence to: A. G. Turner, Walker Institute for Climate System Research, Department of Meteorology, University of Reading, PO Box 243, Earley Gate, Reading, RG6 6BB, UK.

E-mail: a.g.turner@rdg.ac.uk
}

Model with tropical Indo-Pacific heat flux corrections (HadCM3IPFA) performed under $2 \times \mathrm{CO}_{2}$ conditions. Immediately obvious are the multi-decadal timescale changes in ENSO behaviour. Initially, the system of El Niño-La Niña oscillations seems to follow irregular, longperiod events of small amplitude. Later, large amplitude events are more common, which invariably feature a strict biennial period, i.e. La Niña directly following El Niño, and vice versa. This behaviour raises several questions, not least the possible impact of such regime changes should they occur in the real world under increasing $\mathrm{CO}_{2}$ concentrations. The issue of the realism of such multidecadal-timescale changes must also be addressed.

In the observed record, marked climatic shifts were observed in the late-1970s, e.g. in the North Pacific circulation (Trenberth and Hurrell, 1994) and tropical Pacific coral records (Urban et al., 2000). These changes have been associated with shifts in El Niño-La Niña behaviour, ranging from predominantly short period, low amplitude events prior to 1976 and large amplitude events of 4-5 year period afterwards (Guilyardi, 2006). The change in ENSO behaviour can be related to changes in the mean thermocline depth in simple coupled models (Federov and Philander, 2001), however Wang and An (2002) regard observed thermocline changes as uncertain and instead attribute it to decadal timescale variations in the mean state of equatorial winds and associated upwelling. It remains difficult to determine whether changes to the thermocline are directly related to changes in the basic 

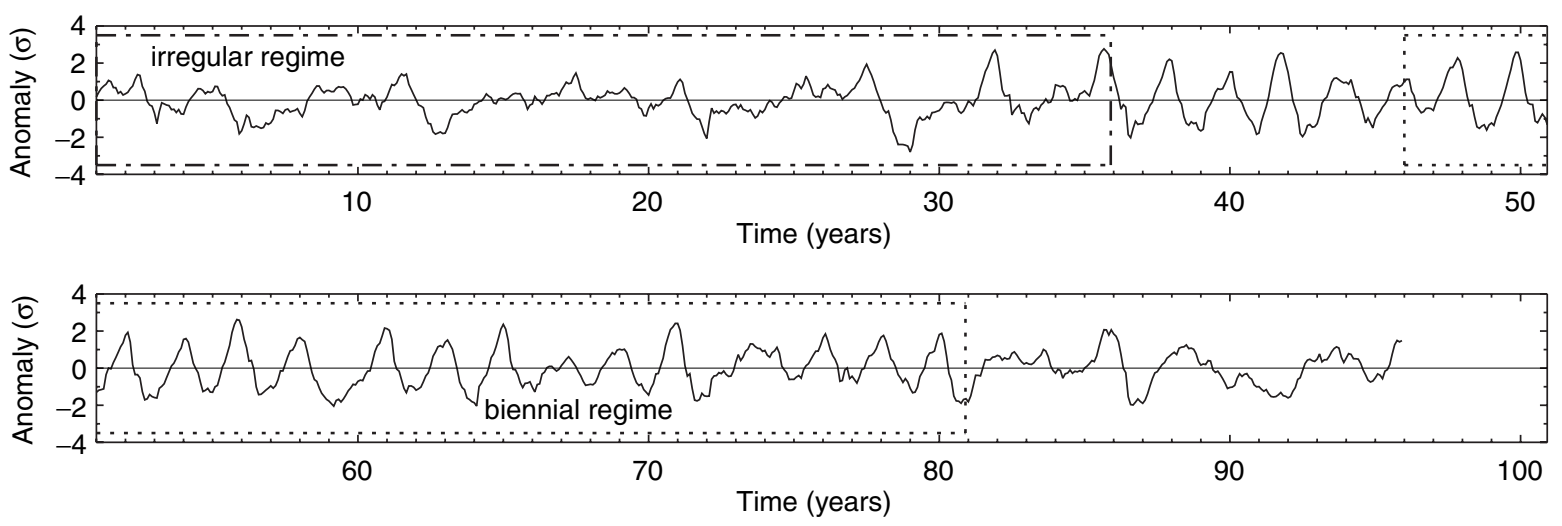

Figure 1. Timeseries of seasonally-adjusted Niño-3 SST anomalies in the HadCM3IPFA $2 \times \mathrm{CO}_{2}$ integration. The regimes chosen for analysis are indicated: irregular (dot-dashed) years 1-35 inclusive and biennial (dotted) years 46-80 inclusive.

state above the surface, or are independent of the local atmosphere and linked to subduction of warmer water from higher latitudes (Guilderson and Schrag, 1998).

Changing ENSO behaviour in the Pacific also influences monsoon variability. The study of Slingo and Annamalai (2000) compares the impact of developing El Niño events in 1982, 1987 and 1997 on the monsoon summer. They argue that particularly strong events such as 1997 could lead to different wind regimes acting on the monsoon, through modulation of the local Hadley circulation. This would help explain the normal monsoon of 1997 despite strong forcing from the Pacific. Annamalai and Liu (2005) also noted that ENSO events pre- and post-1976 affect the monsoon in different ways, those in the earlier period having a more consistent impact.

In addition to the impact of climatic shifts in the background state of the Pacific Ocean, the tropospheric biennial oscillation (TBO) may also have a role to play in future monsoon variability, given the known strong biennial component to Asian monsoon rainfall (see, e.g. Mooley and Parthasarathy, 1984 for India; Shen and Lau, 1995 for China). The biennial tendency of the monsoon-ENSO system seen in the TIS07 study may have a profound impact on monsoon predictability. Indeed Indo-Pacific variability on biennial timescales offers a particularly simple method of prediction, strong monsoons being followed by low rainfall in the following summer season, and vice versa. These Asian summer anomalies persist into the boreal winter season and the Australian monsoon, thus forming a 'monsoon year' representing a strong or weak annual cycle (Yasunari, 1991). Ogasawara et al. (1999) showed that such persistence could be simulated in the MRI coupled GCM. Boreal spring season can feature a change in sign of precipitation anomalies, a manifestation of the predictability barrier (Webster and Yang, 1992). The bienniality of the tropical ocean-atmosphere system is thus governed by the occurrence of the spring transition, as studied by Meehl and Arblaster (2002a, 2002b) and Meehl et al. (2003). Whilst the autumn persistence can be explained by modifications of the climatological progression of convection as it passes from India to Indonesia, mechanisms for the transition are more complex. Meehl (1997) notes the importance of the meridional contrast in tropospheric heating, adjustments to which can alter the large scale forcing for the monsoon flow. Anomalous tropical convection elsewhere can alter the midlatitude circulation, and allow the maintenance of temperature anomalies over South Asia over boreal winter and spring. These are then able to set up anomalous meridional temperature contrasts ahead of the next summer monsoon. Similarly, Osagawara et al. (1999) suggest that a stationary Rossby wave response is established over South Asia due to the Indonesian/Australian monsoon in boreal winter. This low-level anticyclone favours persistent cold air advection over Eurasia, easing the meridional temperature contrast and weakening the following South Asian monsoon. However, other studies such as Loschnigg et al. (2003) and Meehl et al. (2003) highlight the role of Indo-Pacific Ocean processes, in particular that played by the Indian Ocean zonal mode. Anomalous Indian Ocean SSTs are allowed to persist over several seasons via the cross equatorial transportation of heat content anomalies, setting conditions for the Asian monsoon the following summer.

This study considers the impact of doubled $\mathrm{CO}_{2}$ concentration on an integration of the HadCM3 model with partial flux corrections, and the associated biennial tendency of the monsoon-ENSO system under such conditions. The regime-like behaviour seen in Figure 1 is assessed. Section 2 describes details of the integration and data selection process involved in determining the different regimes, whilst section 3 looks at the mean climate differences between the two regimes. Section 4 considers the regimes in terms of simple, theoretical and observed ENSO modes. The overall biennial tendency of the Indo-Pacific region is discussed in section 5, and conclusions are drawn in section 6 .

\section{The GCM integration and data selection}

This study analyses data from the HadCM3IPFA $2 \times$ $\mathrm{CO}_{2}$ integration presented in TIS07 (part I of this paper), which possesses a strong tendency toward biennial conditions. To fully explain the tendencies in the coupled 
system of HadCM3IPFA at $2 \times \mathrm{CO}_{2}$, analysis is also included of the uncorrected model under $1 \times \mathrm{CO}_{2}$ (preindustrial) and $2 \times \mathrm{CO}_{2}$ conditions, in addition to the HadCM3IPFA $1 \times \mathrm{CO}_{2}$ integration from Turner et al. (2005).

ENSO behaviour of the HadCM3IPFA $2 \times \mathrm{CO}_{2}$ integration was shown in Figure 1. To study this behaviour in more detail, the integration has been split into two segments as shown in the figure. The 35-year period of predominantly irregular ENSO behaviour (years 1-35 inclusive), as well as a period during which the biennial oscillation dominates (years 46-80 inclusive), have been selected to be of equal length. That the behaviour in these periods seems reasonably constant allows the usual ENSO statistics to be considered for each in turn. In addition, the impact this biennial tendency may have on the behaviour of the mean monsoon and its predictability will be assessed.

To show that the regime behaviour is a general characteristic of HadCM3IPFA, a second $2 \times \mathrm{CO}_{2}$ integration of HadCM3 has been carried out using different initial conditions, and its Niño-3 behaviour is shown in Figure 2. The biennial tendency is replicated, although there is a more general spread of biennial and irregular events. The transitions between such events appear to be occurring at random. Without flux adjustment, HadCM3 at $2 \times \mathrm{CO}_{2}$ does not present regime-like behaviour or obvious biennial characteristics (TIS07 Figure 8), so the model is clearly capable of realistic ENSO simulation. The remaining analysis will concentrate on the first integration.

\section{Differences in mean climate and ENSO characteristics}

The first assessment of the ENSO regimes depicted in Figure 1 will be to consider the differences between their mean climates. Figure 3 shows the difference in surface temperature, $850 \mathrm{hPa}$ winds and daily precipitation between the annual means of the two regimes. The central equatorial Pacific of the biennial regime is cooler, with bands of slight warming to the north and south. The Indian Ocean north of the equator and
Indian land surface are slightly cooler, whilst the Maritime Continent is warmer, although not significantly so. The lower tropospheric wind differences in Figure 3(b) show a significant Gill response to diabatic heating over the Maritime Continent (Gill, 1980), i.e. both westerly and easterly inflow into the region along the equator. This inflow originates from further across the Pacific than the Indian Ocean, consistent with Gill's model. The warming of the Maritime Continent and increased lowlevel convergence above form part of a coupled system with significant increases in precipitation (Figure 3(c)), of up to $2 \mathrm{~mm} \cdot \mathrm{day}^{-1}$. Although the Indian subcontinent features little precipitation change in the annual mean, summer (JJAS) rainfall over the north west Bay of Bengal and far north of India also see significant increases (up to $2 \mathrm{~mm} \cdot \mathrm{day}^{-1}$, not shown). Changes in the east Pacific are dominated by the boreal winter season, consisting of strong warming and consequent slackening of the zonal temperature gradient on the equator. This surface temperature pattern contributes to a complex wind and precipitation annual mean response in the central to east Pacific.

Beneath the surface of the Pacific, the temperature structure (Figure 4) reveals marked differences. The thermocline depth (measured using the $20^{\circ} \mathrm{C}$ isotherm) is noticeably increased during the biennial regime. This is particularly clear in the east Pacific, where warming at the surface and associated reduced upwelling lead to a thermocline that is some $30 \mathrm{~m}$ deeper. Shoaling of the west Pacific warm pool in the $150-180^{\circ} \mathrm{E}$ region of the biennial regime (as measured by the $28^{\circ} \mathrm{C}$ isotherm) is related to cooling on the surface which extends to depths of more than $100 \mathrm{~m}$, as seen in Figure 4(c). The mean climate difference of the two regimes, particularly in the surface and subsurface temperature fields, has important repercussions which will be returned to later.

Returning to ENSO and behaviour in the east Pacific, Figure 5 shows statistics of the Niño-3 region. Figure 5(a) indicates that the biennial regime undergoes a smaller annual cycle than the irregular regime, although this change is much smaller than that due to $2 \times \mathrm{CO}_{2}$, which is in the range $1.5-2{ }^{\circ} \mathrm{C}$. The month-by-month interannual variability is considered in Figure 5(b), where the
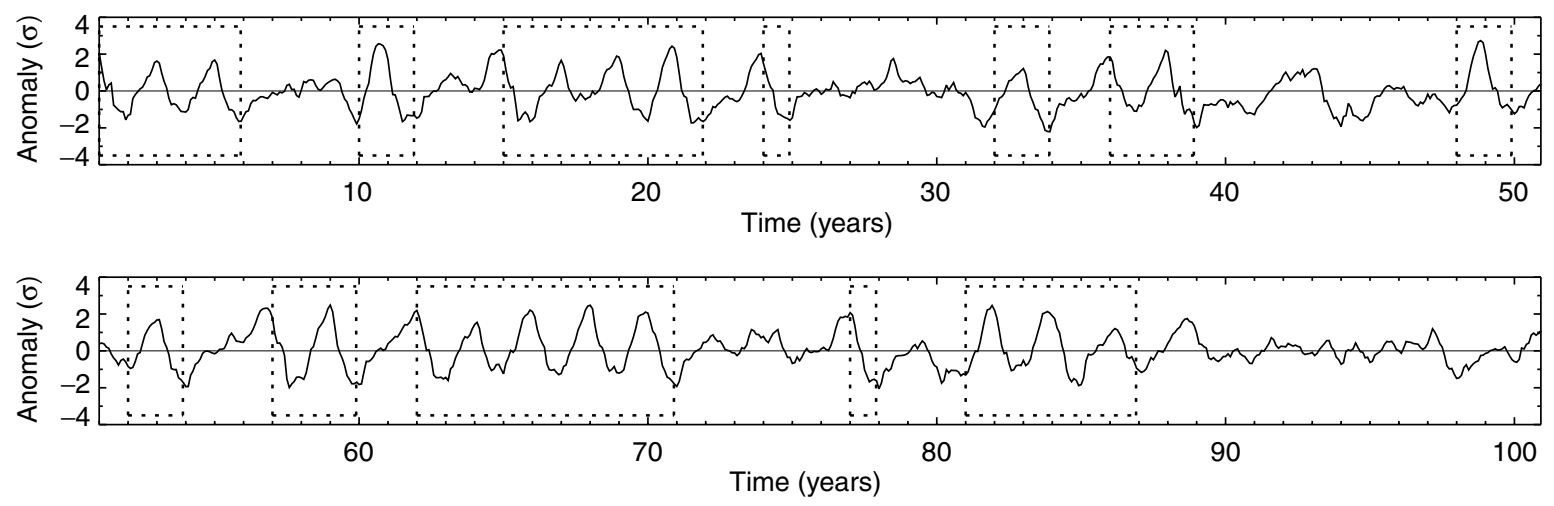

Figure 2. Timeseries of seasonally-adjusted Niño-3 SST anomalies in the 2 nd HadCM3IPFA $2 \times \mathrm{CO}_{2}$ integration. Boxed regions are indicative of biennial oscillation. 

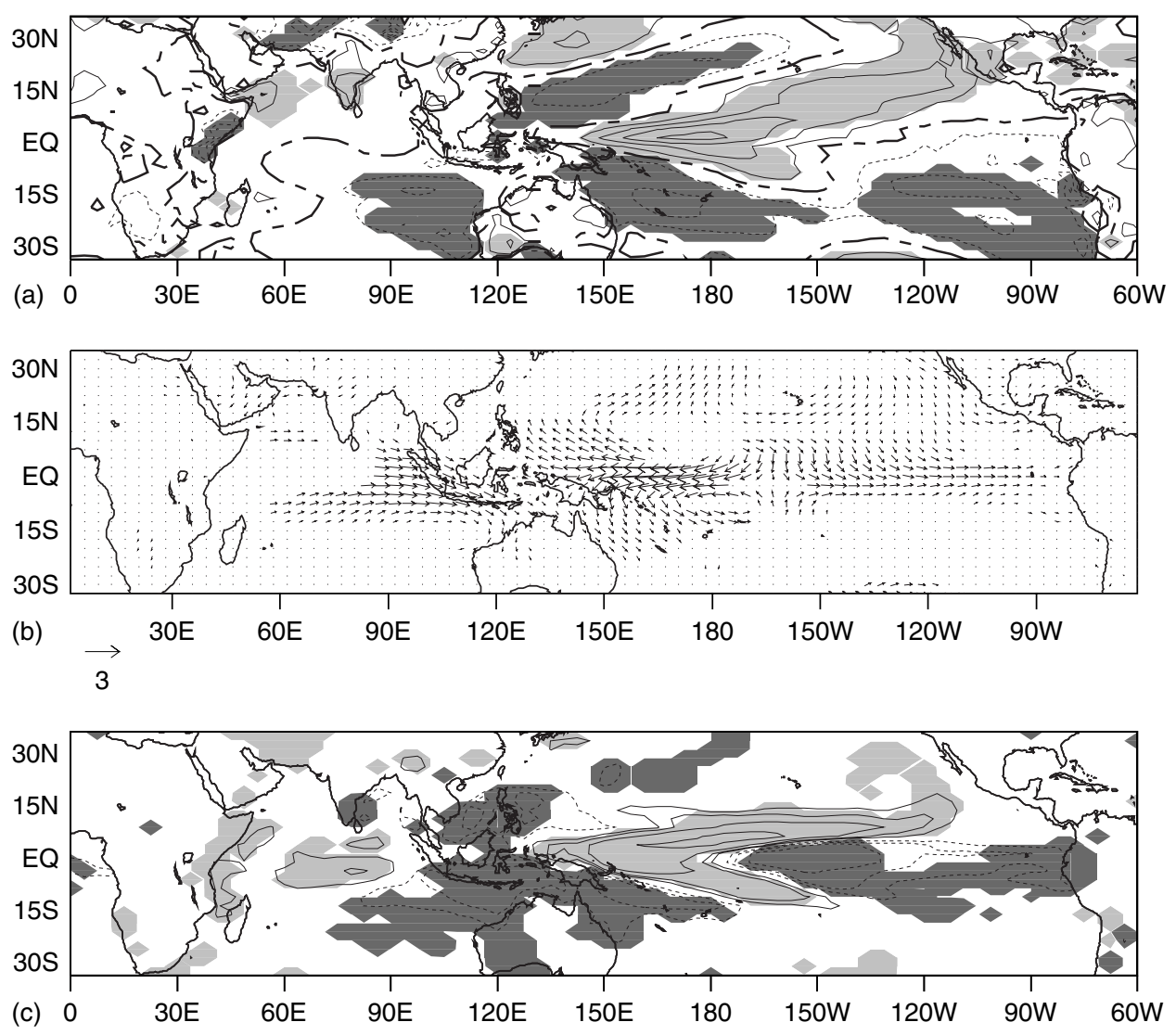

Figure 3. HadCM3IPFA $2 \times \mathrm{CO}_{2}$ annual mean climate difference between the biennial and irregular regimes selected in Figure 1 for (a) surface temperature (K), (b) $850 \mathrm{hPa}$ winds $\left(\mathrm{ms}^{-1}\right)$ and (c) daily precipitation $\left(\mathrm{mm} \mathrm{day}^{-1}\right)$. Negative (positive) contours are solid (dashed). Zero line is long-dashed on temperature plot, contour interval is $0.2 \mathrm{~K}$. Unit wind vector is $3 \mathrm{~ms}^{-1}$. Zero line is omitted from precipitation plot and contours are at $\pm 0.5,1,2,4,8 \mathrm{~mm} \mathrm{day}^{-1}$. Light (dark) shading indicates significance at the $95 \%$ level using a student t-test over negative (positive) anomalies. All indicated wind vectors are significant at this level.

biennial ENSO oscillation is clearly much more strongly phase locked to the seasonal cycle than during the irregular oscillation. Variability at the spring minima is also slightly lower in the biennial regime. A measure of this is the seasonal phase lock index (inter-monthly standard deviation of the curves in Figure 5(b)), values of which are $0.49^{\circ} \mathrm{C}$ for the biennial regime whilst only $0.20^{\circ} \mathrm{C}$ during the irregular period. These findings are consistent with Guilyardi (2006) who found that a smaller annual cycle could be more easily disturbed, and would allow El Niño-La Niña oscillations of larger amplitude, in his study of the multi-model ensemble assessed for the IPCC AR4. (These are hereafter named the IPCC AR4 integrations and are made available through the WCRP CMIP3 multi-model dataset archived at PCMDI.) Further confirmation can be found by looking at power spectra, which are shown for each regime and the model integrations for comparison in Figure 5(c). The ENSO oscillation is seen to be stronger than the annual cycle in the biennial regime, whilst the irregular regime features low power across a broad range of ENSO frequencies. Looking at the normalising factors confirms that the annual cycle is indeed weaker during the biennial regime. The spectra also indicate that the doubling of $\mathrm{CO}_{2}$ in HadCM3 has caused no overall shift in the interannual peak, consistent with studies such as Zelle et al. (2005) and Guilyardi
(2006), which found no significant or consistent changes in ENSO period. The tendency toward shorter oscillations in HadCM3IPFA $2 \times \mathrm{CO}_{2}$ is supported, however, by Merryfield (2006) who noted such a change when measuring the median period in IPCC AR4 integrations.

In order to further understand the differences between El Niño and its interaction with the annual cycle in the two regimes, the behaviour at depth is considered over time. Figure 6 shows the evolution of $20^{\circ} \mathrm{C}$ isotherm depth anomalies (D20), a proxy for thermocline depth and thus heat content of the upper ocean, in each of the regimes. The irregular period shows more evidence of the annual cycle in the east Pacific, seasonal upwelling bringing cold waters to the near surface and raising the $20^{\circ} \mathrm{C}$ isotherm. The annual cycle dominates over ENSO for much of the regime, with the exception of La Niña-shoaling in winters of years 12, 21 and 28. Also evident are persistent El Niño events spanning the central Pacific, most notably from year 5 onwards. During the biennial regime, shoaling and deepening on ENSO timescales clearly over-powers the annual cycle in the east Pacific, confirming the dominance of ENSO over the annual cycle seen in Figure 5(c). Finally, the biennial regime suggests fully basinwide eastward propagation at depth in both ENSO phases, an important point which will be returned to later. 
(a)

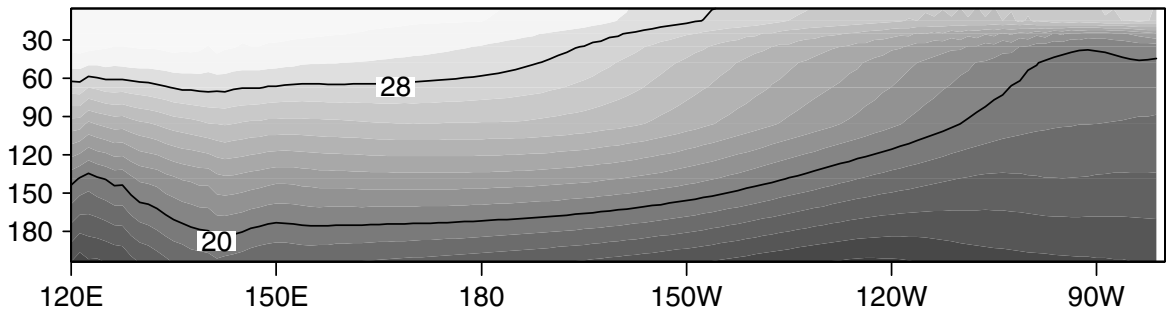

(b)
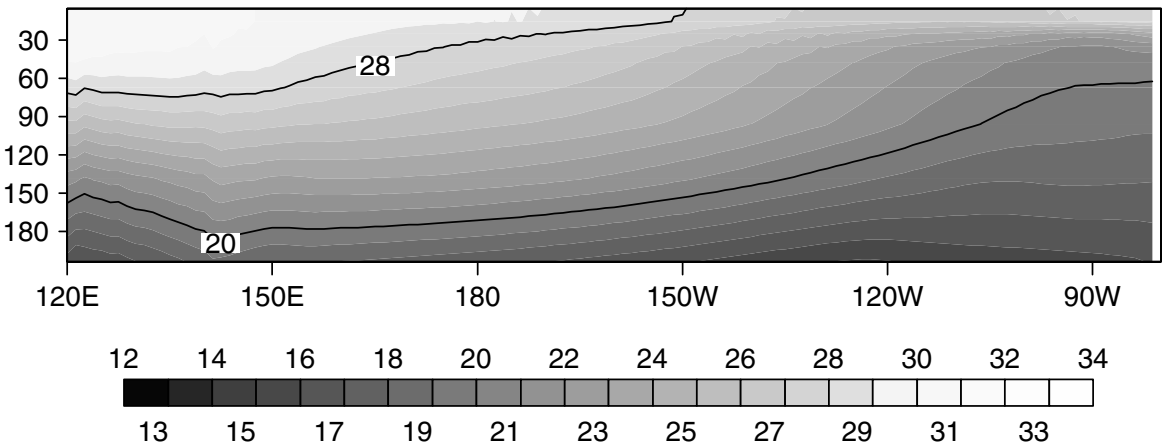

(c)

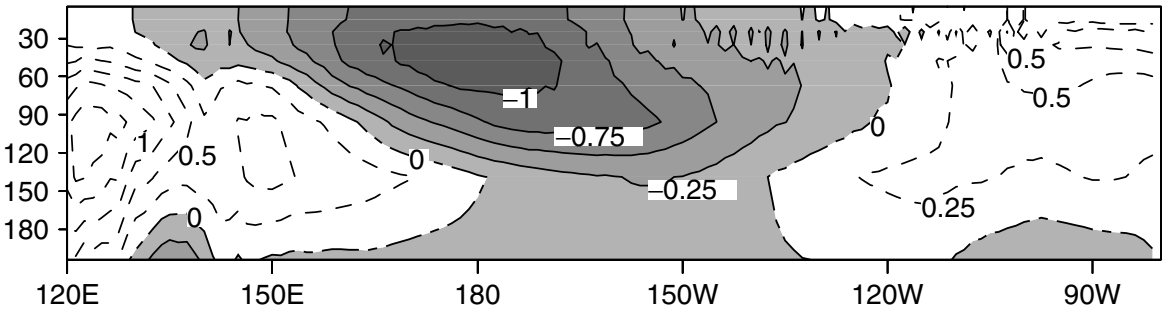

Figure 4. Annual mean thermocline profile along the equatorial Pacific $\left(0.625^{\circ} \mathrm{N}-0.625^{\circ} \mathrm{S}\right)$ for the (a) irregular and (b) biennial regimes where $20^{\circ} \mathrm{C}$ and $28{ }^{\circ} \mathrm{C}$ isotherms are highlighted. In (c) the biennial minus irregular annual mean is plotted, contour interval $0.25^{\circ} \mathrm{C}$, positive contours dotted, negative values shaded.

\section{Classifying regimes in terms of simple model and observed ENSO modes}

Before considering the reasons for the biennial tendency in this model, some simple model studies will be used to draw analogies with the irregular and biennial regimes. Jin (1997) used a simple coupled basin-wide oscillator of the tropical (Pacific) ocean-atmosphere system to explain the low frequency nature of ENSO in terms of a recharge oscillator, essentially incorporating delayed oscillator theory (Suarez and Schopf, 1988; Battisti, 1988) without an explicit time delay. The phase change of the oscillation is instead governed by recharging and discharging of heat from the thermocline, where the equatorial heat content (zonal mean thermocline depth) increases prior to El Niño, and falls (discharges) afterwards. The usual positive (Bjerknes) feedback is included as the growth mechanism.

Jin (1997) highlights the difficulty in classifying ENSO as a simple oscillator behaving as a single mode, and describes different regimes ranging from a limit cycle perturbed by noise, to a decaying oscillator sustained by noise. The regularity of the biennial regime in HadCM3IPFA, with its strong phase locking to the annual cycle (Figure 5(b)), suggests it is analogous to the self-excited limit cycle as in Jin (1997). An assessment of the high frequency characteristics of the two regimes (not shown) reveals that the irregular regime features increased variability, both on synoptic (westerly wind event) and intraseasonal (MJO) timescales. This is consistent with the stochastic forcing required to excite El Niño in Jin's model. Wang et al. (1999) define El Niño modes in a similar fashion in their stochastically forced nonlinear dynamics model.

In both studies, the transition between these two states is governed by the atmosphere-ocean coupling strength, a critical bifurcation value marking the switch between the two regimes. In Jin's system, coupling strength is specified as a constant of proportionality between zonal wind stress and SST anomaly. Whilst a detailed examination of bifurcation points in our coupled system will be the subject of another study, here the coupling strength will be estimated as the linear-fit gradient of the response of monthly zonal surface wind anomalies in the Niño-4 region to Niño-3 SST anomalies, after Guilyardi et al. (2004). To make sense of the separate influences of increased $\mathrm{CO}_{2}$ and the applied flux corrections, the gradients for all model integrations and the two regimes are summarized in Table I. Not only do the values indicate increased coupling when the model undergoes flux adjustment, but also when $\mathrm{CO}_{2}$ concentration is doubled. Thus, both factors should provide a tendency towards a limit-cycle, consistent with the higher coupling strength during the biennial rather than irregular regime. 

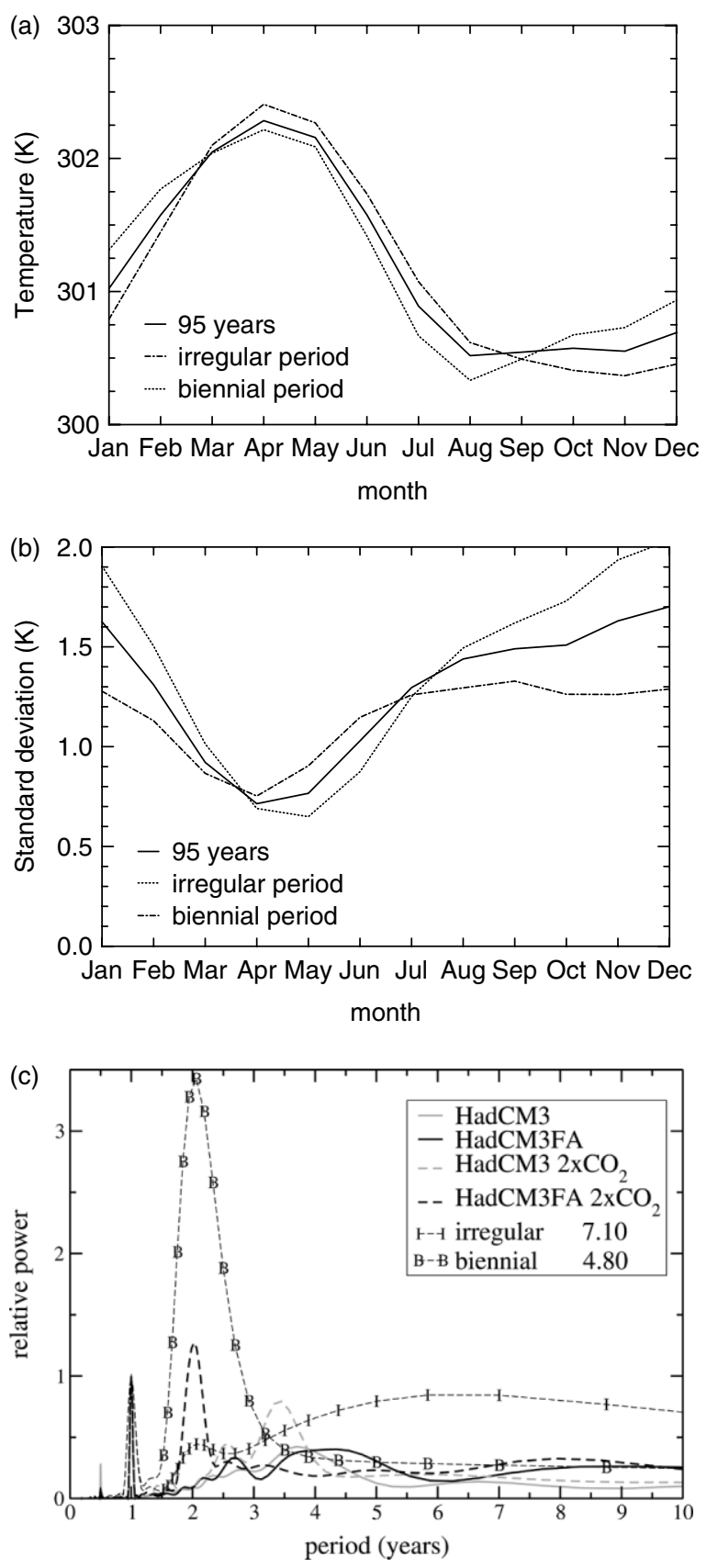

Figure 5. Niño-3 region SST behaviour for the irregular and biennial regimes of HadCM3IPFA $2 \times \mathrm{CO}_{2}$ : (a) SST seasonal cycle, (b) seasonal cycle of interannual standard deviations, (c) power spectra of SST normalized to the annual cycle with normalizing factors for each regime shown in the legend. The spectra for model integrations are also shown for reference. B and I symbols are removed below 18 months for clarity.

Some simple models of the Pacific basin (e.g. Zebiak and Cane, 1987) suggest that increasing coupling strength should give oscillations of longer period. This is contrary to the period shortening seen in HadCM3IPFA $2 \times \mathrm{CO}_{2}$ and will be addressed later.

Neelin et al. (1998) describe observed El Niño modes as lying on a spectrum of behaviour. At one end, the thermocline or basinwide mode develops through a feedback between remote winds and the equatorial thermocline, encompassing the west Pacific and featuring
Table I. Gradient of Niño-4 surface zonal wind anomalies vs. Niño-3 SST anomalies $\left(\Delta u_{10}^{\prime} / \Delta S S T^{\prime}\right) .1 \times \mathrm{CO}_{2}$ values are taken from TIS05 Figure 11.

\begin{tabular}{lcc}
\hline Model & $1 \times \mathrm{CO}_{2}$ & $2 \times \mathrm{CO}_{2}$ \\
\hline HadCM3 & 0.74 & 0.85 \\
HadCM3IPFA & 0.88 & 0.89 \\
Irregular & - & 0.80 \\
Biennial & - & 0.92 \\
\hline
\end{tabular}

subsurface eastward propagation. This mode incorporates the delayed oscillator mechanism (Suarez and Schopf, 1988; Battisti, 1988), the timescale being governed by basinwide oceanic adjustment. At the other extreme SST modes more closely related to zonal advection and upwelling across the thermocline, and generated by local SST-wind interaction in the central and east Pacific, prevail. These modes feature surface east-to-west propagation of SST anomalies. Jin (1997) identifies the observed SST and basinwide ocean-adjustment modes with his simple oscillatory modes mentioned earlier (irregular and limit-cycle regimes respectively). Neelin et al. (1998) attribute observed ENSO behaviour to a hybrid of these modes, and Federov and Philander (2001) too suggest that the dominance of each simple mode may vary over time, governed by the relative influence of differing mechanisms. The modes will be referred to here as $S$-mode (based on SST advection) and T-mode (based on remote thermocline feedbacks) after Guilyardi (2006).

In order to determine whether these observed modes are relevant to behaviour in HadCM3, we use a tool introduced by Trenberth and Stepaniak (2001) to measure El Niño mode evolution over long time series. Their trans-Niño index (TNI) measures the SST gradient across the equatorial Pacific basin: the difference between normalised SST anomalies in the far east and west Pacific, Niño-1 $+2\left(0-10^{\circ} \mathrm{S}, 90-80^{\circ} \mathrm{W}\right)$ and Niño-4 $\left(5^{\circ} \mathrm{N}-5^{\circ} \mathrm{S}\right.$, $\left.160^{\circ} \mathrm{E}-150^{\circ} \mathrm{W}\right)$ regions respectively. Thus

$$
\mathrm{TNI}=\mathrm{SST}_{\mathrm{N}_{1+2}}-\mathrm{SST}_{\mathrm{N} 4} .
$$

The TNI is then lag-correlated with Nino-3 SST anomalies, both indices being normalized, and passed through a 12-year moving window. (Trenberth and Stepaniak (2001) used Nino-3.4 to represent average SST conditions, but here Nino-3 is used in common with the rest of this study. Being only slightly further east, this makes no qualitative difference to the result.) As one component is effectively the mean of SSTs along the equator and the other represents zonal gradient, at zero lag they will be orthogonal. Figure 7 shows the analysis applied to the HadISST observed dataset (Rayner et al., 2003). At negative lags (TNI leading Niño-3), a negative correlation indicates largely eastward surface propagation, whereas a positive correlation indicates predominantly westward propagation. The reverse is true at positive lags. Before the late-1970s, the correlation suggests westward propagation, related to the S-mode by Guilyardi (2006). After 
(a)

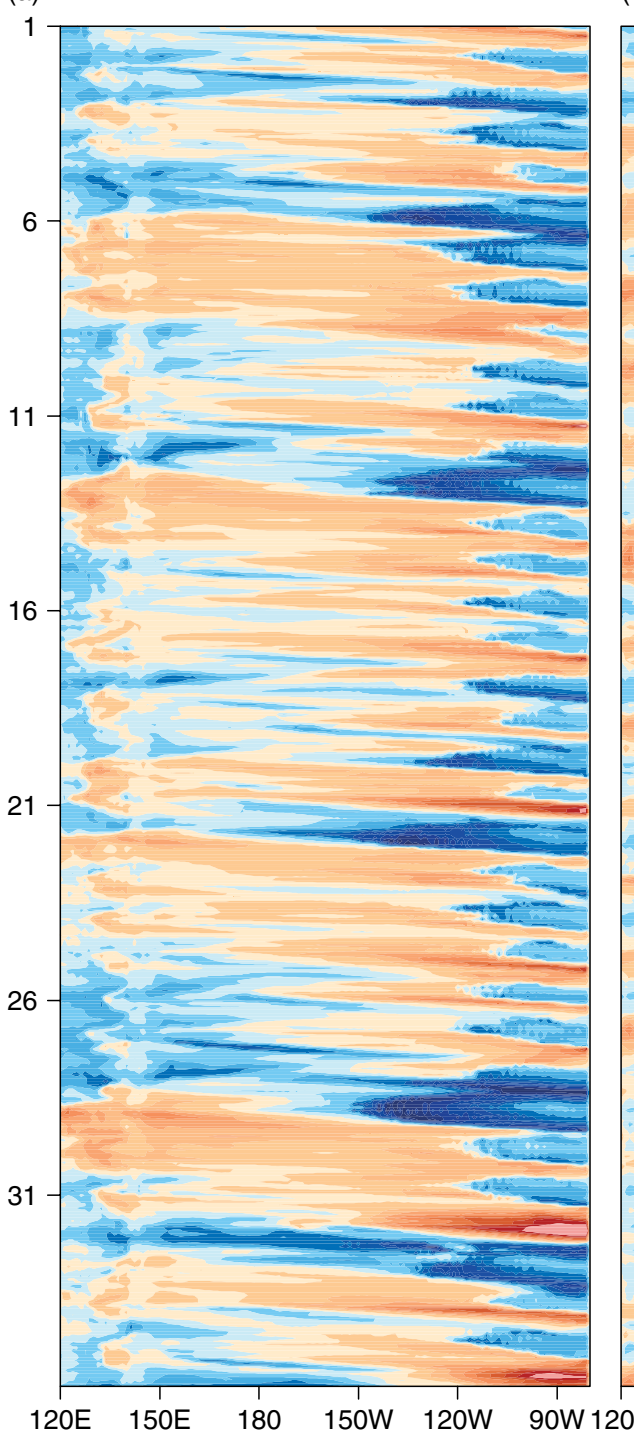

(b)

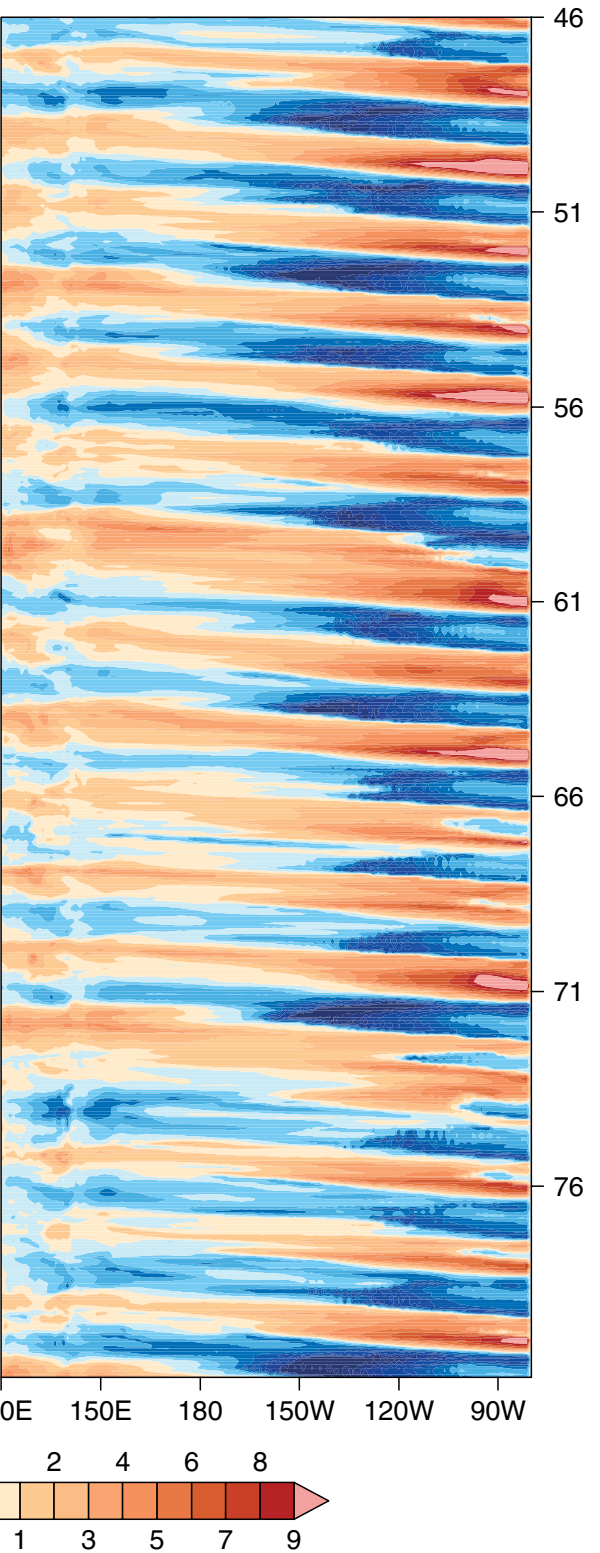

Figure 6. Evolution of equatorial $\left( \pm 0.625^{\circ} \mathrm{N}\right)$ Pacific $20^{\circ} \mathrm{C}$ isotherm depth anomalies in (a) irregular and (b) biennial regimes of the HadCM3IPFA $2 \times \mathrm{CO}_{2}$ integration. Units are dam.

the late-1970s, Niño-3 leads the TNI and the T-mode is prevalent. A change in periodicity is very evident, being 2-3 years in the early portion and 4-5 years after the late-1970s. At this stage, given the short period, one may associate the TBO with ENSO prior to the late-1970s. As we shall see later however, such a simple association is invalid. Trenberth and Stepaniak (2001) note that the changes in El Niño amplitude, period and propagation are concurrent with abrupt climatic changes in circulation over the tropical Pacific.

Figure 8 shows the same lag-correlation for each of the fixed $\mathrm{CO}_{2}$ forcing model integrations, in order to demonstrate tendencies caused by the combination of flux adjustments and increased $\mathrm{CO}_{2}$. Whilst there may be some concern about evaluating the Nino- $1+2$ index (coastal waters) in coarse resolution GCMs such as

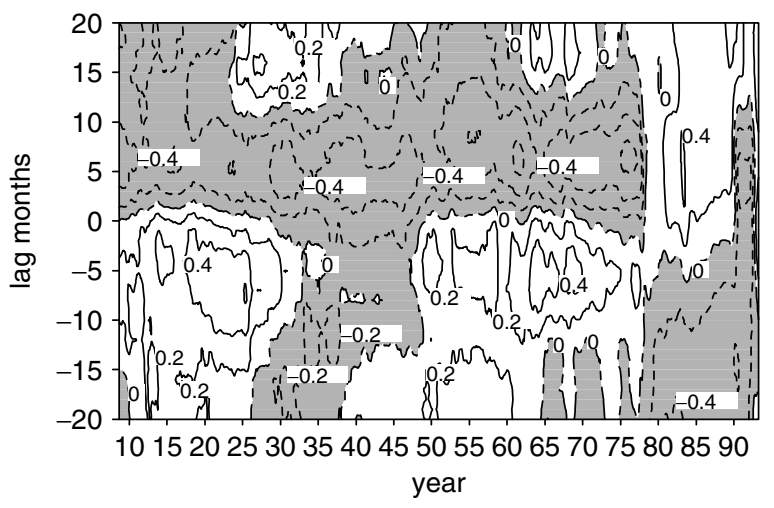

Figure 7. Lag-correlation of the trans-Niño index (TNI) with Niño-3 SST anomalies in the HadISST observational dataset from 1901-1998. See text for index definitions. A 12-year moving window is applied to smooth the data. Negative lags refer to TNI leading Niño-3. 
HadCM3, its choice makes no qualitative difference to the results. (Indeed Hovmoeller diagrams of equatorial SST anomaly propagation have been checked for consistency with Figure 8.) In the study of the IPCC AR4 models by Guilyardi (2006), HadCM3 was one of the few models able to simulate changes of mode during $1 \times \mathrm{CO}_{2}$ control simulations. According to Guilyardi (2006), this suggests that models such as HadCM3 are most likely to represent the simple mechanisms that might lead El Niño characteristics to change with the changing climate.

El Niño behaviour becomes more eastward when $\mathrm{CO}_{2}$ concentrations are doubled, concurring with Guilyardi (2006). This behaviour is noted irrespective of flux adjustment: Figures 8(c) and (d) both show correlations that are more positive at positive lag-times than their $1 \times \mathrm{CO}_{2}$ counterparts are (Figures 8(a) and (b)). The introduction of flux adjustments also promotes eastward propagation, although to a lesser degree than increased $\mathrm{CO}_{2}$. The tendency toward eastward propagation can be quantified in a simple manner, by taking the time-mean correlation value at all lags, after Guilyardi (2006). This is illustrated for HadISST and the model integrations in Figure 9. The modelled tendency towards T-mode ENSO is accompanied by an increase in El Niño amplitude (see TIS07 Table IV), concurring with the observed record (Guilyardi 2006).

Some studies suggest possible factors that may explain the tendency toward T-mode behaviour under basic state changes such as global warming. In a theoretical study based on the Zebiak-Cane model, Federov and Philander
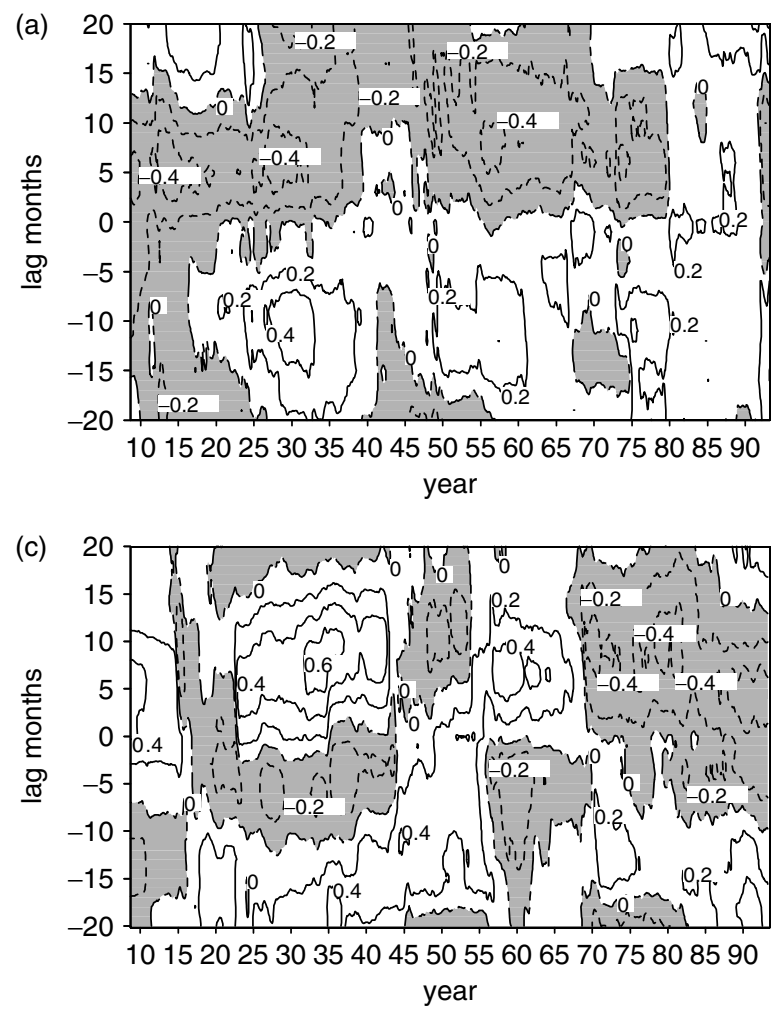

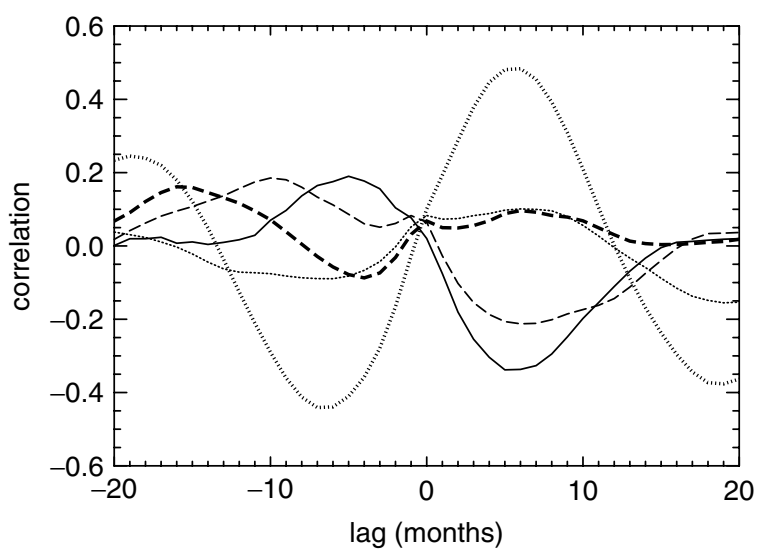

Figure 9. Time-mean TNI vs. Niño-3 SST correlation at each lag for HadISST observations (solid) and HadCM3 (dashed) and HadCM3IPFA (dotted). $2 \times \mathrm{CO}_{2}$ simulations are double thickness.

(2001) show that for moderate thermocline depths, weakening of the mean wind allows deepening of the thermocline in the east, leading to the dominance of vertical movements of the thermocline (over zonal advection and entrainment terms) in their SST equation. This favours the T-mode with its inherent basin-wide dynamics over the S-mode, which relies on local gradients in SST. We have already shown in TIS07 that slackening of the trade winds occurs in response to both flux correction and $\mathrm{CO}_{2}$ increases, although these signals are not uniform across the entire Pacific basin. In any case, the El Niñolike mean response to climate change seen in TIS07, i.e. reduced zonal temperature gradient on the equator, is
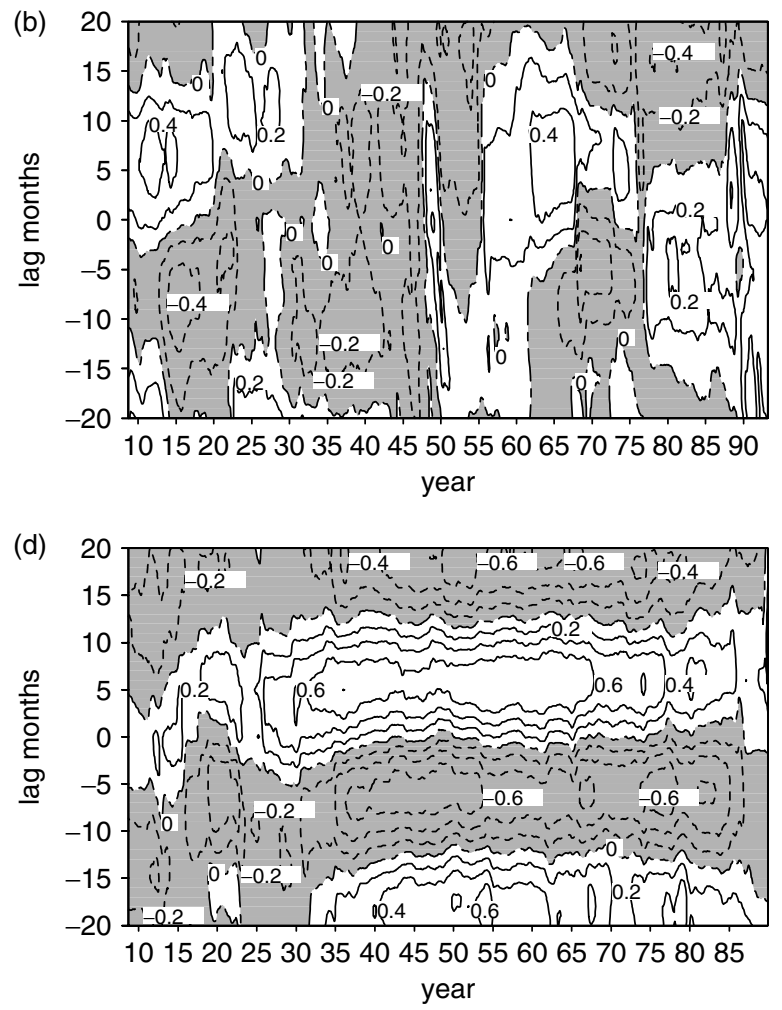

Figure 8. As Figure 7 but for (a) HadCM3 and (b) HadCM3IPFA model integrations at $1 \times \mathrm{CO}_{2}$, (c) HadCM3 and (d) $\mathrm{HadCM} 3 \mathrm{IPFA}$ at $2 \times \mathrm{CO}_{2}$. Note the different $x$-axis scale for the HadCM3IPFA $2 \times \mathrm{CO}_{2}$ data. 
consistent with a weaker contribution from zonal advection at the surface. Also, deepening of the thermocline in the east has been found to occur as a response to both climate change and flux adjustment (TIS07), consistent with Federov and Philander (2001). In a study of several coupled GCMs at $2 \times \mathrm{CO}_{2}$, Merryfield (2006) agrees that the zonal advection feedback component of ENSO growth will diminish under conditions where the zonal temperature gradient decreases (El Niño-like warming). In addition, the generation of SST anomalies by the upwelling feedback (the T-mode) is found in his study to be the natural result of a lag between surface warming and warming at depth. This is consistent with both global warming and the imposition of large heat flux adjustments at the ocean surface in the central Pacific.

Other studies such as Wang and An (2002) study patterns of mean winds before and after the climate shift of the late-1970s. Their post-shift minus pre-shift wind difference is of the opposite sign to the biennial minus irregular climate of Figure 3(b), but consistent with increased upwelling in the east Pacific. The climatological wind difference between the biennial and irregular regimes (Figure 3(b)) is consistent, however, with a deepened thermocline in the east (seen in Figure 4), and reduced zonal temperature gradient on the surface (Figure 3(a)). Thus, the argument of Federov and Philander (2001) would support further tendency to the T-mode during the biennial regime.

HadCM3IPFA $2 \times \mathrm{CO}_{2}$, whilst clearly tending towards eastward propagating ENSO on the surface (and evident at depth during the biennial regime in Figure 6(b)), is representing the temporal behaviour in a different way to observed T-mode events (with their typical 4-5 year period). This tendency to oscillate at biennial periods will be explained in the next section.

\section{Reasons for the biennial tendency in HadCM3IPFA}

Given that a period of irregular oscillation returns after the biennial regime (Figure 1, and also the intermittent periods of biennial oscillation in Figure 2), a simple spinup to the imposition of flux adjustments can be ruled out. Guilyardi et al. (2004) state that weak intraseasonal activity and basic state errors can limit stochastic forcing of El Niño, making it too regular. However, flux adjustments in HadCM3 have been shown to improve both these inadequacies (Inness et al., 2003; Turner et al., 2005) so these are unlikely reasons in this case. Earlier work with different versions of the Unified Model (Collins, 2000a, 2000b) saw increased ENSO activity at biennial timescales at $4 \times \mathrm{CO}_{2}$ in $\mathrm{HadCM} 2$, but not HadCM3. This different response was not attributable to the removal of global flux corrections between HadCM2 and HadCM3. Wu and Kirtman (2004) found that the COLA-coupled GCM exhibited a strong biennial ENSO, which they relate to a combination of the strong impact of the Indian monsoon on ENSO, and the restricted meridional scale of the wind response to ENSO events. These explanations will be pursued here.

In the delayed oscillator (Suarez and Schopf, 1988), Rossby waves are driven westward along the thermocline, forced by atmospheric heating over a warm SST anomaly. These reflect back as upwelling Kelvin waves, acting to damp the original heating as they return to the east. Using a coupled model, Kirtman (1997) argues that high-amplitude Kelvin wave reflections will be more likely to cancel the original heating anomaly and hence shorten the oscillation period. Kirtman (1997) noted the key role of Rossby waves originating further off the equator (outside $\sim \pm 7^{\circ}$ ). Travelling more slowly than the gravest Rossby mode, these waves would interfere with the reflected eastbound Kelvin wave, reducing its amplitude and thus lengthening the ENSO period. Models with a reduced meridional scale of the wind response to ENSO heating anomalies would fail to capture these off-equatorial Rossby waves. Clearly, the longitudinal position of the warm SST anomaly could also affect the ENSO period, eastward displacement increasing the ocean wave propagation time and thus lengthening the period as in Wang and An (2002). In a comprehensive study of ENSO variability in twentieth century coupled GCM simulations, Capotondi et al. (2006) measure these effects. While no clear relation emerges between either longitudinal position or meridional scale and ENSO period, Capotondi et al. (2006) used multiple linear regression to predict the period of each model, using these as inputs. These predicted periods match closely with measured periods in the models.

In our framework, the systematic westward bias of SST variability in the equatorial Pacific, common to many coupled models, would favour a short ENSO period. However the flux adjustments act to displace this eastward (see e.g. Turner et al., 2005 Figure 13). Following Capotondi et al. (2006), the meridional scale of the zonal wind stress response to ENSO is estimated by regressing $\tau_{x}$ onto the Niño-3 index. The zonal mean is then taken across the Pacific $\left(154^{\circ} \mathrm{E}-120^{\circ} \mathrm{W}\right)$, and the distance between the zero crossings is calculated. At $2 \times \mathrm{CO}_{2}$ these are $13.75^{\circ}$ and $13.5^{\circ}$ for HadCM3 3 and HadCM3IPFA respectively, similar to the quoted figure of $14.2^{\circ}$ for HadCM3 (L19) in Capotondi et al. (2006). These are both at the upper end of the range of meridional scales in the GCMs in Capotondi et al. (2006). There thus appears to be scant evidence of changes in the structure of ENSO itself which would support shorter periods.

Of much greater significance to the biennial tendency is the impact of strong monsoon forcing on the tropical Pacific. Studies linking monsoon forcing to biennial behaviour include Kim and Lau (2001) who found the key mechanism was coupling between ENSO and monsoon wind forcing in the west Pacific. They introduced strong summer monsoon wind forcing into a simple model framework to help initiate ENSO phase change and force biennial activity, with the monsoon acting as a pacemaker. Lau and Wu (2001) noted that this strong monsoon forcing was likely to be adjusting the West 
Pacific Anticyclone (WPA) near the Philippines, an impact which could initiate ENSO phase change by wind forcing in the equatorial west Pacific.

Given the monsoon's influence on the Pacific Ocean through features such as the WPA, and evidence for biennial oscillation in both the east Pacific (Figure 1) and the Asian summer monsoon regions (TIS07, Figure 5(b)), the monsoon-ENSO system should be analysed as coupled components of the tropospheric biennial oscillation (TBO). This is defined as the tendency for the Asian summer monsoon to alternate between relatively strong and weak years. We follow the analysis of Meehl and Arblaster (2002a), Loschnigg et al. (2003), Meehl et al. (2003) and others, a relatively strong monsoon year being defined as

$$
\mathrm{DMI}_{n-1}<\mathrm{DMI}_{n}>\mathrm{DMI}_{n+1},
$$

and a weak year,

$$
\mathrm{DMI}_{n-1}>\mathrm{DMI}_{n}<\mathrm{DMI}_{n+1},
$$

where $\mathrm{DMI}_{n}$ is the summer (JJAS) dynamical monsoon index (Webster and Yang, 1992) for year $n$. The DMI has been used rather than precipitation as wind forcing has a more direct impact on ENSO phase change.

The DMI time series for HadCM3IPFA $2 \times \mathrm{CO}_{2}$ was shown in TIS07 Figure 4. Those years in the figure satisfying Equations $(2,3)$ are recognised as strong and weak years respectively, a strong (or weak) Asian summer monsoon being labelled JJA(0). The period surrounding the summer is split into seasonal intervals, from $\operatorname{MAM}(0)$ (the season before the summer monsoon), through $\operatorname{SON}(0), \operatorname{DJF}(+1)$ and $\operatorname{MAM}(+1)$, to $\operatorname{JJA}(+1)$ (the summer one year later). Strong and weak 18-month cycles are composited from the data, after Loschnigg et al. (2003). From these, a seasonal evolution of the TBO is generated from strong minus weak differences of surface temperature, $850 \mathrm{hPa}$ wind and precipitation, and shown in Figure 10. The evolution described in Figure 10 highlights the important persistence and transition seasons common in other studies. Strong precipitation anomalies are seen to persist across boreal autumn, as first noted by Troup (1965) and later in Meehl (1987), passing from the Indian summer (Figure 10(b)) to the Australian winter monsoon (Figure 10(d)). During boreal spring (Figure 10(e)), a transition takes place (e.g. Meehl and Arblaster, 2001). This leads to a weak Somali Jet and low mean monsoon precipitation when compared to the previous summer, coupled together with warm Pacific SST anomalies.

The figure also emphasises the importance of coupling between the monsoon-ENSO system and the Indian Ocean dipole or zonal mode (IOZM), together with associated up- and downwelling. The IOZM was first thought to be independent of ENSO (Saji et al., 1999), but other studies such as Loschnigg et al. (2003) have found that this is frequently not the case. Indeed Figure 10(c) supports Loschnigg et al. (2003) and Meehl et al. (2003) by suggesting that the Indian Ocean is an inherent part of the TBO mechanism, its lagged response to Pacific SST anomalies acting as a regulator for monsoon strength. To test this further, correlations are performed between indices governing the strength of ENSO (Niño-3 SSTA), the monsoon (DMI), and the Indian Ocean Zonal Mode (IOZM). The monsoon and ENSO are most strongly correlated during the summer months, thus JJAS-averaged DMI and Niño-3 SSTA are used. The Indian Ocean dipole peaks during boreal autumn, thus the SON mean of the IOZM index is used (defined as west $\left(50-70^{\circ} \mathrm{E}\right.$, $\left.10^{\circ} \mathrm{S}-10^{\circ} \mathrm{N}\right)$ minus east $\left(90-110^{\circ} \mathrm{E}, 10^{\circ} \mathrm{S}\right.$-EQ) Indian Ocean SSTA in Saji et al., 1999). Correlations between these measures are shown in Table II. As noted in TIS07, the teleconnection between monsoon dynamics and east Pacific SSTs is increased by both flux adjustment and enhanced $\mathrm{CO}_{2}$ forcing. Note that, although stronger during the biennial regime, even the irregular regime of HadCM3IPFA $2 \times \mathrm{CO}_{2}$ features a stronger DMI-Niño-3 teleconnection than HadCM3 $2 \times \mathrm{CO}_{2}$. In Figure 11(a) the lag-correlations between summer monsoon indices and Niño-3 are shown. The dynamical teleconnection is slightly stronger during the biennial regime, however when precipitation is used as an index, the teleconnection weakens dramatically during the irregular regime. This further highlights the complex relationship between monsoon dynamics and precipitation highlighted in TIS07.

Similarly, ENSO and the Indian Ocean dipole are more strongly coupled under the influences of climate change and flux adjustment. Comparing the IOZM and monsoon, Annamalai et al. (2007) found increased correlations between SSTs west of Sumatra (the eastern pole of the IOZM), and Indian rainfall in some of the increased $\mathrm{CO}_{2}$ IPCC AR4 simulations. In contrast, our experiments show $2 \times \mathrm{CO}_{2}$ forcing to have a negligible impact. However, equatorial flux corrections strengthen the IOZM vs. DMI correlation, hence a strong Asian summer monsoon in the flux corrected model is more likely to initiate a negative dipole during autumn.

The Indian Ocean dipole has thus been shown to be reasonably correlated with both aspects of the monsoonENSO system in this modelling framework. During the biennial ENSO regime, the dipole is much more strongly coupled to both the monsoon and ENSO, highlighting its importance in the Indo-Pacific regions on biennial timescales. In addition, the TBO evolution in Figure 10 can be constructed for each regime separately. When this is done (not shown), the most striking difference is the lack of Indian Ocean SST anomalies during boreal spring in the irregular regime, the essential season for influencing ENSO anomaly growth (Webster and Yang, 1992).

The understanding of the active nature of the Indian Ocean and its effect on ENSO has greatly improved in recent studies. In a 200-year control simulation of the SINTEX-F1 coupled GCM, Kug et al. (2006) divide El Niño events into those which are well coupled with the Indian Ocean and those that are independent. Their 

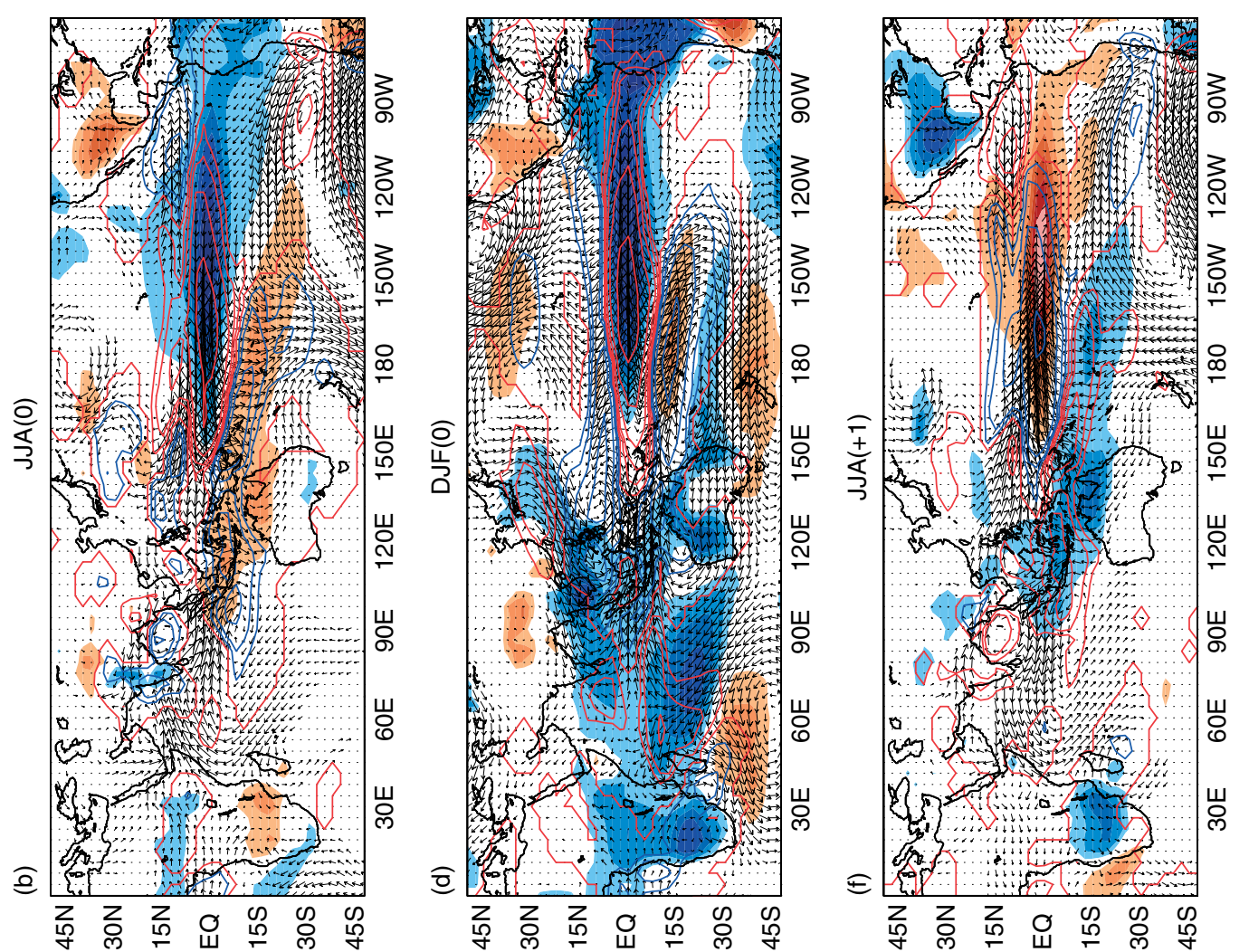

兽

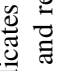

要

然远

뜬

तิ

帘

तิ

言.

密

कon $\overrightarrow{0}$

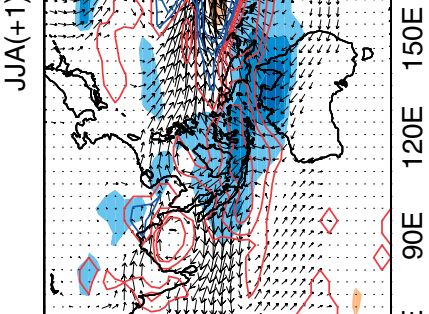

흠

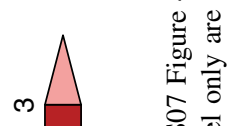

m.

$\sim$ N

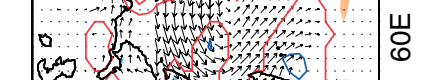

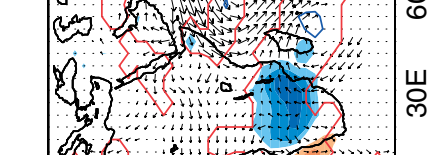

$\overline{8}$

造

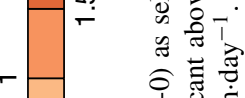

$r$

$\Xi$

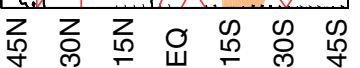
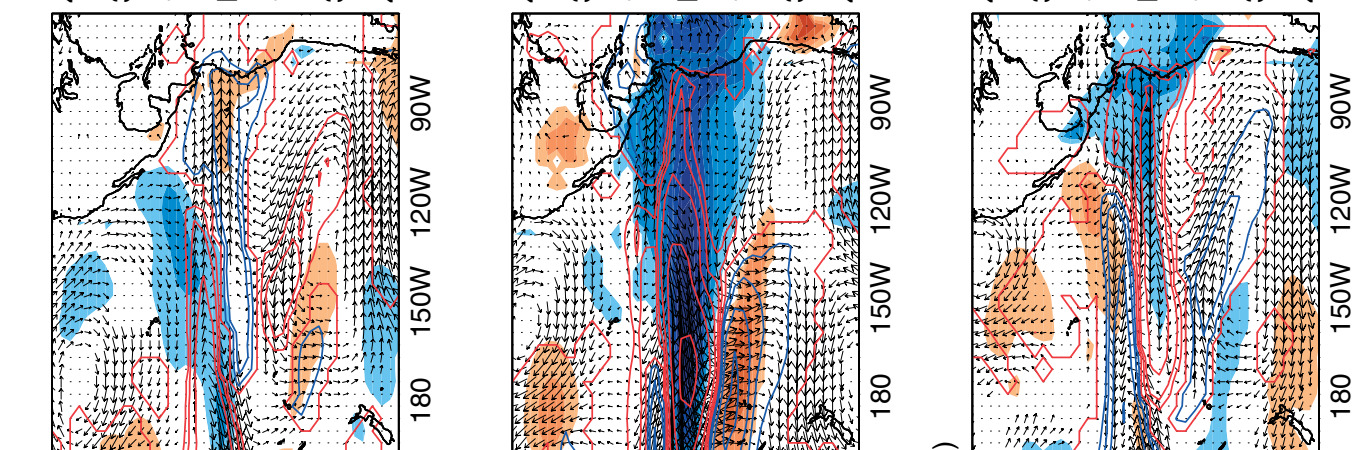

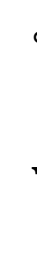
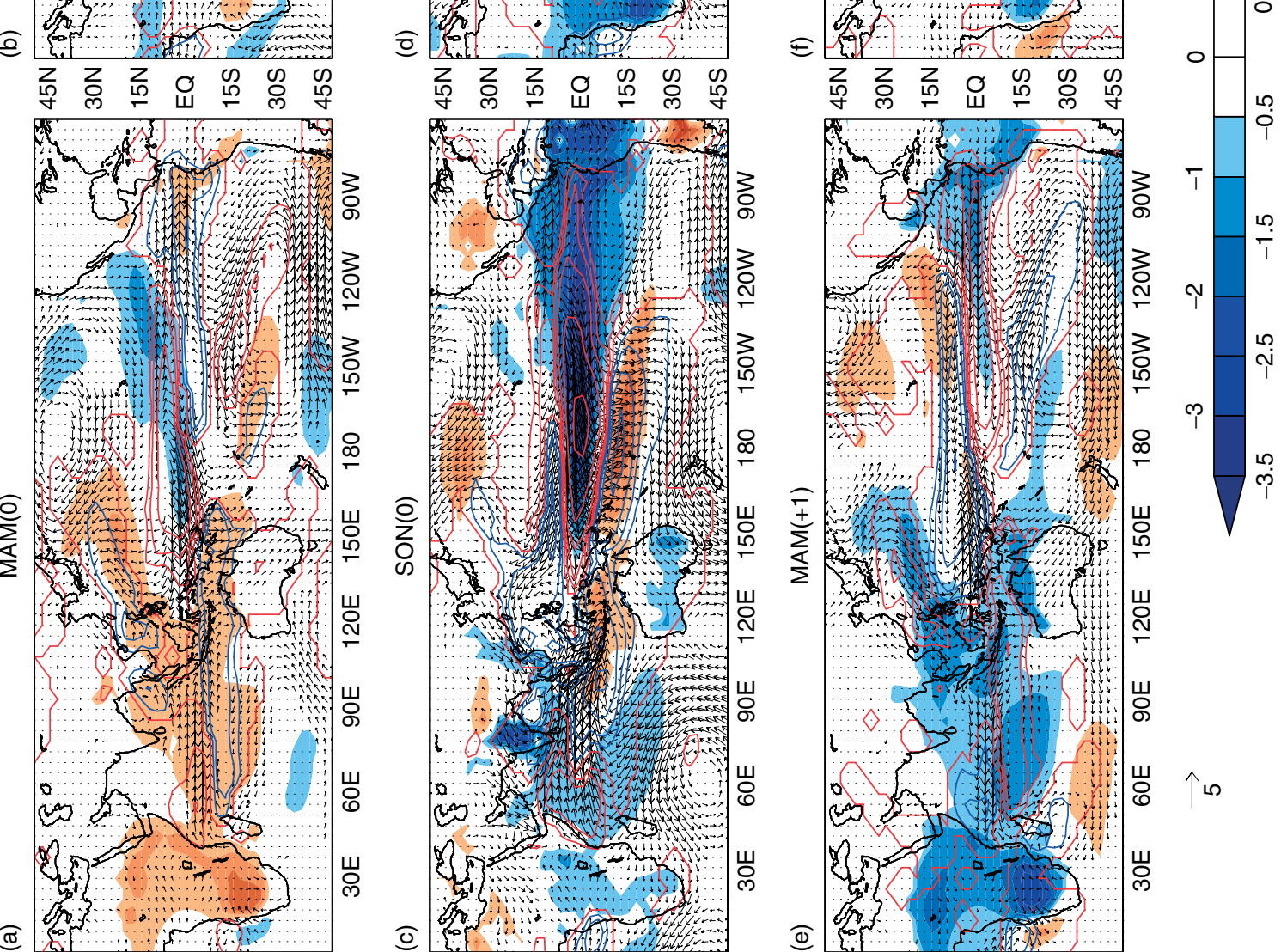

药营

5.

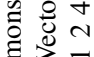

可

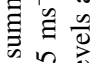

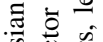

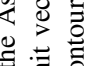

更

旅

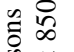

每

要

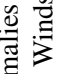

害

ळ

竞言

品

홍

on

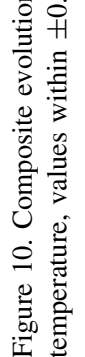


Table II. Correlations between the Indian Ocean dipole (IOZM), monsoon (DMI) and east Pacific SST (Niño-3) indices. DMI and Niño-3 SSTA are JJAS values whilst IOZM is averaged over SON.

\begin{tabular}{lccc}
\hline Model & $\begin{array}{c}\text { IOZM } \\
\text { vs DMI }\end{array}$ & $\begin{array}{c}\text { IOZM } \\
\text { vs Niño-3 }\end{array}$ & $\begin{array}{c}\text { Niño-3 } \\
\text { vs DMI }\end{array}$ \\
\hline HadCM3 1 $\times \mathrm{CO}_{2}$ & -0.58 & 0.51 & -0.36 \\
HadCM3IPFA 1 $\times \mathrm{CO}_{2}$ & -0.72 & 0.61 & -0.69 \\
HadCM3 2 $\times \mathrm{CO}_{2}$ & -0.60 & 0.58 & -0.57 \\
HadCM3IPFA 2 $\times \mathrm{CO}_{2}$ & -0.69 & 0.66 & -0.82 \\
Irregular & -0.58 & 0.45 & -0.79 \\
Biennial & -0.74 & 0.74 & -0.85 \\
\hline
\end{tabular}
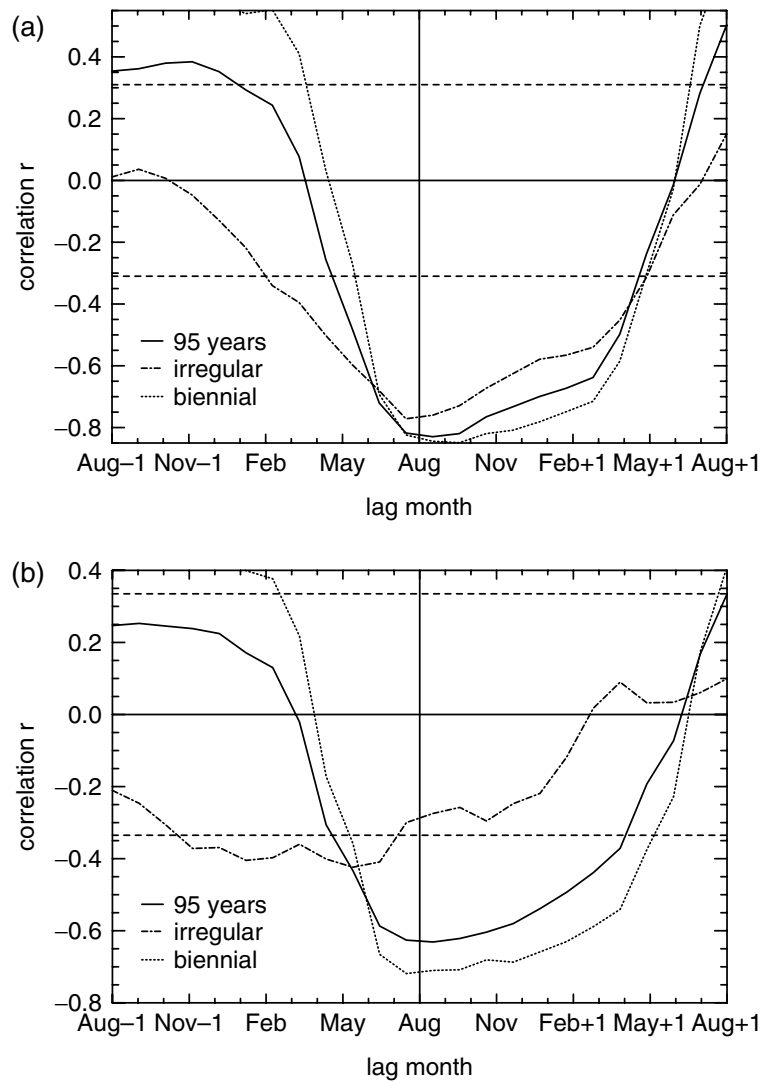

Figure 11. Lag-correlations between Niño-3 SST anomalies and summer (JJAS) monsoon indices (a) the DMI, (b) All-India rainfall (for definition see TIS07). Outside the dashed lines, the regime correlations are significant at the $95 \%$ level.

composite of well-coupled El Niño events decays significantly more quickly to La Niña conditions (and is therefore more biennial) than the decoupled case. The mechanism for such an influence is outlined by Kug and Kang (2006). In the well-coupled case, the boreal autumn dipole decays and spreads basinwide, generating wind anomalies in the east Indian and west Pacific Oceans via an atmospheric Kelvin wave response (e.g. the eastward progression of western Indian Ocean negative SST anomaly from Figure $10 \mathrm{SON}(0)$ to $\operatorname{DJF}(+1)$, associated with westerly wind anomalies in the west Pacific). These wind anomalies act to counter the anomalous trade winds

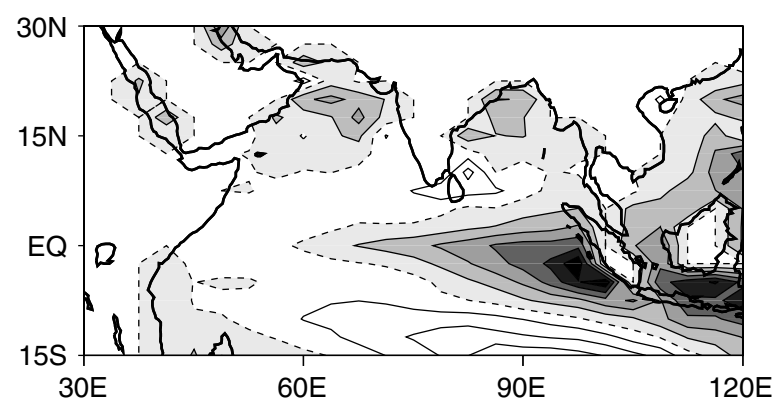

Figure 12. Composite biennial minus irregular difference of autumn (SON) SSTs during El Niño onset years when Niño-3 anomaly exceeds $+1 \sigma$. Negative (positive) contours (un)shaded. Zero line is dashed, contour interval $0.2^{\circ} \mathrm{C}$

associated with ENSO (strong trades and La Niña in Figure $10 \mathrm{DJF}(+1)$ ) bringing about rapid phase change. Annamalai et al. (2005) highlight the importance of the decay of the Indian Ocean dipole to a basinwide anomaly of the same sign as the ENSO phase. They use an AGCM study to show that the dipole alone could not generate an atmospheric Kelvin wave of suitable magnitude to initiate wind forcing in the west Pacific. To further highlight the role of the Indian Ocean dipole in HadCM3IPFA, the Indian Ocean was studied in El Niño onset years. By compositing the boreal autumn season for all events exceeding $+1 \sigma$ from the mean in each regime, and taking their difference (Figure 12) we see that during El Niño events in the biennial regime there is clear evidence of a strong zonal mode in the Indian Ocean, particularly its eastern pole.

In addition to the studies mentioned earlier linking monsoon wind forcing in the west Pacific and increased biennial ENSO variability (Kim and Lau, 2001; Lau and Wu, 2001), Chung and Nigam (1999) demonstrated that inclusion of Asian summer monsoon heating anomalies in the Zebiak-Cane model of the Pacific region led to a positive feedback between the two regions. This feedback acts to increase the occurrence of ENSO events without altering their seasonal phase-locking. Instead of trying to parameterise the effects of the Indian sector into models of the Pacific, Kug and Kang (2006) extend the domain of the recharge oscillator (Jin, 1997) to incorporate Indian Ocean SST and thermocline behaviour. Analysis of the three coupled equations in their system shows that increased coupling between the two basins significantly shortens the period of oscillation, favouring biennial timescales. The monsoon forcing acting on the west Pacific is strengthened by increased $\mathrm{CO}_{2}$ concentrations in HadCM3, in addition to increases brought about by reducing systematic model biases. In the absence of other changes to the Pacific Ocean which would act to shorten the ENSO period in the flux-adjusted model (no further meridional confinement of the zonal wind stress response to ENSO) this increased Indo-Pacific coupling remains the likely explanation for the biennial tendency of HadCM3IPFA $2 \times \mathrm{CO}_{2}$. The importance of the Indian Ocean to the Asian-Australian monsoon system is thus highlighted by this study, especially in 
determining the sign of interannual variation during the following summer. This is consistent with the findings of Meehl and Arblaster (2002b), that the Indian Ocean aids biennial transitions.

\section{Conclusions}

An integration of the partially flux-corrected Unified Model (HadCM3IPFA) has been run under $2 \times \mathrm{CO}_{2}$ conditions to assess the possible impact of systematic model bias on future climate predictions of Asian Summer Monsoon behaviour (see TIS07). The integration features a remarkable tendency to biennial oscillation of the monsoon-ENSO system, especially in one integration where quite distinct irregular and biennial ENSO regimes are found. Study of the irregular and biennial regimes has revealed some marked differences. A smaller annual cycle during the biennial regime, together with stronger phase locking of ENSO to the annual cycle, leads to a greater propensity for El Niño events to occur.

The two ENSO modes seen in the model fit with those predicted in theory in some sense. Consistent with the recharge oscillator of Jin (1997), we postulate that an irregular mode gives way to a self-excited limit cycle as the strength of air-sea coupling increases. This coupling strength, measured as the surface wind response to SST anomalies in the east Pacific, is found to be increased both by the use of flux adjustments and $2 \times \mathrm{CO}_{2}$ forcing, and is noticeably stronger during the biennial regime.

In observations, a spectrum of behaviour ranging from westward propagating local modes (S-modes) to eastward propagating basinwide modes (T-modes) is found. In this modelling framework, tendency towards T-mode behaviour is noted both under $2 \times \mathrm{CO}_{2}$ conditions and with flux adjustment, a tendency which can be explained by a decrease in the mean trade winds and zonal temperature gradient of the equatorial Pacific. This allows vertical motion of the thermocline to dominate over zonal advection of SST anomalies, consistent with the theoretical study by Federov and Philander (2001).

The tendency toward biennial oscillation in HadCM3IPFA $2 \times \mathrm{CO}_{2}$ apparently contradicts the longer period oscillations simulated in simple models of the Pacific basin as atmosphere-ocean coupling strength is increased. Delayed oscillator-type ENSO modes seen in the recent observed record (e.g. 1997), reliant on the response of the entire Pacific basin to ocean wave dynamics, are also usually of longer period. The biennial tendency of HadCM3IPFA at $2 \times \mathrm{CO}_{2}$ is not confined to the Pacific Ocean however, also incorporating the AsianAustralian monsoon system as part of the tropospheric biennial oscillation (TBO) and the Indian Ocean dipole. In common with other studies, anomalous conditions during the Asian summer monsoon persist until boreal winter when they lie over north Australia. A sign change to the monsoon anomalies occurs during boreal spring.
The biennial tendency, increased by both doubled $\mathrm{CO}_{2}$ and flux adjustment, is related to strong monsoon wind forcing over the west Pacific, leading to rapid phase change of ENSO anomalies further east. Fundamental to this is the strong coupling found between the Indian and Pacific Oceans, aided by the growth and eventual decay of the Indian Ocean dipole to a basinwide anomaly of the same sign as the current phase of ENSO. As shown by Kug and Kang (2006), this strong coupling between the Indian and Pacific Oceans leads to oscillations on biennial timescales in simple model and observed systems. The extension of simple ENSO models to the Indian sector in this way dispels the contradiction noted earlier and highlights the importance of the Indian Ocean, with its lagged response to ENSO acting as a regulator of monsoon strength in the following year.

The flux adjustment technique has revealed not only a magnified mean and variability response to increased greenhouse gas concentrations (see TIS07), but also a strong tendency toward biennial oscillation of the monsoon-ENSO system, a tendency which can only lead to greater extremes of drought and flood in monsoon affected societies. The presence of distinct regimes in the integration studied here presents a particularly interesting manifestation of climate change. This ability to change between regimes would lead to greater uncertainty in future projections of climate, and the transition between them should be studied in more detail to determine their cause in GCMs. Additionally, while the delayed oscillator mechanism does not preclude T-mode events of a two-year period, their occurrence here does raise some interesting questions. Not least is the persistence of coupled GCMs to simulate the El Niño-La Niña variability maxima too far west, even when flux adjustments are used. Perhaps more realistic GCMs with ENSO peaking in the east Pacific would not feature such a strong biennial tendency, even when strongly coupled to the Indian sector. Clearly those coupled GCMs which exhibit biennial tendencies (e.g. in Nanjundiah et al., 2005) should be studied more closely.

\section{Acknowledgements}

A. G. Turner was supported through a $\mathrm{PhD}$ studentship provided by NERC's National Centre for Atmospheric Science (NCAS), and is now funded via the EUENSEMBLES project as part of the NCAS-Climate programme. Julia Slingo and Pete Inness are members of NCAS, Pete Inness being partially funded by the EUDYNAMITE project. A. G. Turner is grateful for useful discussions with Tim Li. The authors thank the associate editor, Richard Seagar, Jerry Meehl, and a further anonymous reviewer for their useful comments which have helped improve this manuscript. The HadISST dataset was obtained from the Met Office and computing resources were provided by CSAR for running the Unified Model. 


\section{References}

Annamalai H, Hamilton K, Sperber KR. 2007. The South Asian Summer Monsoon and Its Relationship with ENSO in the IPCC AR4 Simulations. J. Climate 20: 1071-1092. DOI: 10.1175/JCLI4035.1.

Annamalai H, Liu P. 2005. Response of the Asian summer monsoon to changes in El Niño properties. Q. J. R. Meteorol. Soc. 131: 805-831. DOI: $10.1256 /$ qj.04.08.

Annamalai H, Xie SP, McCreary JP, Murtugudde R. 2005. Impact of Indian Ocean Sea Surface Temperature on Developing El Niño. J. Climate 18: 302-319. DOI: 10.1175/JCLI-3268.1.

Battisti DS. 1988. Dynamics and Thermodynamics of a Warming Event in a Coupled Tropical Atmosphere-Ocean Model. J. Atmos. Sci. 45: 2889-2919. DOI: 10.1175/1520-0469(1988)045<2889:DATOAW> 2.0.CO;2.

Capotondi A, Wittenberg A, Masina S. 2006. Spatial and temporal structure of Tropical Pacific interannual variability in 20th century coupled simulations. Ocean Modelling 15: 274-298. doi:10.1016/j.ocemod.2006.02.004.

Chung C, Nigam S. 1999. Asian Summer Monsoon - ENSO Feedback on the Cane-Zebiak Model ENSO. J. Climate 12: 2787-2807. DOI: 10.1175/1520-0442(1999)012<2787:ASMEFO > 2.0.CO;2.

Collins M. 2000a. The El Niño-Southern Oscillation in the Second Hadley Centre Coupled Model and Its Response to Greenhouse Warming. J. Climate 13: 1299-1312. DOI: 10.1175/15200442(2000)013<1299:TENOSO > 2.0.CO;2

Collins M. 2000b. Understanding uncertainties in the response of ENSO to greenhouse warming. Geophys. Res. Lett. 27: 3509-3512.

Federov AV, Philander SG. 2001. A Stability Analysis of Tropical Ocean-Atmosphere Interactions: Bridging Measurements and Theory for El Niño. J. Climate 14: 3086-3101. DOI: 10.1175/15200442(2001)014<3086:ASAOTO > 2.0.CO;2.

Gill AE. 1980. Some simple solutions for heat-induced tropical circulation. $Q$. J. R. Meteorol. Soc. 106: 447-462. DOI: 10.1002/qj.49710644905.

Guilderson TP, Schrag DP. 1998. Abrupt Shift in Subsurface Temperatures in the Tropical Pacific Associated with Changes in El Niño. Science 281: 240-243. DOI: 10.1126/science.281.5374.240.

Guilyardi E. 2006. El Niño - mean state - seasonal cycle interactions in a multi-model ensemble. Clim. Dyn. 26: 329-348. DOI: 10.1007/s00382-005-0084-6.

Guilyardi E, Gualdi S, Slingo J, Navarra A, Delecluse P, Cole J, Madec G, Roberts M, Latif M, Terray L. 2004. Representing El Niño in Coupled Ocean-Atmosphere GCMs: The Dominant Role of the Atmospheric Component. J. Climate 17: 4623-4629. DOI: 10.1175/JCLI-3260.1.

Inness PM, Slingo JM, Guilyardi E, Cole J. 2003. Simulation of the Madden-Julian Oscillation in a coupled general circulation model. Part II: The role of the basic state. J. Climate 16: 365-382. DOI: 10.1175/1520-0442(2003)016<0365:SOTMJO > 2.0.CO;2

Jin F-F. 1997. An equatorial Ocean recharge paradigm for ENSO. Part I: conceptual model. J. Atmos. Sci. 54: 811-829. DOI: 10.1175/15200469(1997)054<0811:AEORPF>2.0.CO;2.

Kim K-M, Lau K-M. 2001. Dynamics of monsoon-induced biennial variability in ENSO. Geophys. Res. Lett. 28: 315-318.

Kirtman BP. 1997. Oceanic Rossby Wave Dynamics and the ENSO Period in a Coupled Model. J. Climate 10: 1690-1704. DOI: 10.1175/1520-0442(1997)010<1690:ORWDAT > 2.0.CO;2.

Kug J-S, Kang I-S. 2006. Interactive Feedback between ENSO and the Indian Ocean. J. Climate 19: 1784-1801. DOI: 10.1175/JCLI3660.1.

Kug J-S, Li T, An S-I, Kang I-S, Luo J-J, Masson S, Yamagata T. 2006. Role of the ENSO-Indian Ocean coupling on ENSO variability in a coupled GCM. Geophys. Res. Lett. 33: L09710. doi:10.1029/2005GL024916.

Lau K-M, Wu HT. 2001. Principal Modes of Rainfall-SST Variability of the Asian Summer Monsoon: A reassessment of the MonsoonENSO Relationship. J. Climate 14: 2880-2895. DOI: 10.1175/15200442(2001)014<2880:PMORSV>2.0.CO;2

Loschnigg J, Meehl GA, Webster PJ, Arblaster JM, Compo GP. 2003. The Asian Monsoon, the Tropospheric Biennial Oscillation, and the Indian Ocean Zonal Mode in the NCAR CSM. J. Climate 16: 1617-1642. DOI: $10.1175 / 1520$ 0442(2003)016<1617:TAMTTB > 2.0.CO;2.

Meehl GA. 1987. The annual cycle and interannual variability in the tropical Pacific and Indian Ocean regions. Mon. Weather Rev. 115: 27-50. DOI: 10.1175/1520-0493(1987) $115<0027$ :TACAIV $>$ 2.0.CO;2
Meehl GA. 1997. The South Asian Monsoon and the Tropospheric Biennial Oscillation. J. Climate 10: 1921-1943. DOI: 10.1175/15200442(1997)010<1921:TSAMAT > 2.0.CO;2.

Meehl GA, Arblaster JM. 2001. The Tropospheric Biennial Oscillation and Indian Monsoon Rainfall. Geophys. Res. Lett. 28: 1731-1734.

Meehl GA, Arblaster JM. 2002a. The Tropospheric Biennial Oscillation and Asian-Australian Monsoon Rainfall. J. Climate 15: 722-744. DOI: $10.1175 / 1520-0442(2002) 015<0722$ :TTBOAA > 2.0.CO;2

Meehl GA, Arblaster JM. 2002b. Indian Monsoon GCM Sensitivity Experiments Testing Tropospheric Biennial Oscillation Transition Conditions. J. Climate 15: 923-944. DOI: $10.1175 / 1520$ 0442(2002)015<0923:IMGSET>2.0.CO;2.

Meehl GA, Arblaster JM, Loschnigg J. 2003. Coupled OceanAtmosphere Dynamical Processes in the Tropical Indian and Pacific Oceans and the TBO. J. Climate 16: 2138-2158. DOI: 10.1175/2767.1.

Meehl GA, Collins WD, Boville BA, Kiehl JT, Wigley T M L, Arblaster JM. 2000. Response of the NCAR climate system model to increased $\mathrm{CO}_{2}$ and the role of physical processes. J. Climate 13: 1879-1898. DOI: $10.1175 / 1520$ 0442(2000)013<1879:ROTNCS $>2.0 . C O ; 2$.

Merryfield WJ. 2006. Changes to ENSO under $\mathrm{CO}_{2}$ Doubling in a Multimodel Ensemble. J. Climate 19: 4009-4027. DOI: 10.1175/JCLI3834.1.

Mooley DA, Parthasarathy B. 1984. Fluctuations in All-India summer monsoon rainfall during 1871-1978. Clim. Change 6: 287-301. DOI: $10.1007 / \mathrm{BF} 00142477$.

Nanjundiah RS, Vidyunmala V, Srinivasan J. 2005. The impact of increase in $\mathrm{CO}_{2}$ on the simulation of tropical biennial oscillations (TBO) in 12 coupled general circulation models. Atmospheric Science Letters 6: 183-191. DOI: 10.1002/asl.115.

Neelin JD, Battisti DS, Hirst AC, Jin F-F, Wakata Y, Yamagata T, Zebiak SE. 1998. ENSO theory. J. Geophys. Res. 103 14261-14290. DOI: 10.1029/97JC03424.

Ogasawara N, Kitoh A, Yasunari T, Noda A. 1999. Tropospheric Biennial Oscillation of ENSO-Monsoon System in the MRI Coupled GCM. J. Meteorol. Soc. Jpn 77: 1247-1270.

Rayner NA, Parker DE, Horton EB, Folland CK, Alexander LV, Rowell DP, Kent EC, Kaplan A. 2003. Global analyses of sea surface temperature, sea ice, and night marine air temperature since the late nineteenth century. J. Geophys. Res. 108(D14): 4407. DOI: 10.1029/2002JD002670.

Saji NH, Goswami BN, Vinayachandran PN, Yamagata T. 1999. A dipole mode in the tropical Indian Ocean. Nature 401: 360-363.

Shen S, Lau K-M. 1995. Biennial Oscillation Associated with the East Asian Summer Monsoon and Tropical Sea Surface Temperatures. J. Meteorol. Soc. Jpn 73: 105-124.

Slingo JM, Annamalai H. 2000. 1997: The El Niño of the Century and the Response of the Indian Summer Monsoon. Mon. Weather Rev. 128: 1778-1797. DOI: 10.1175/15200493(2000)128<1778:TENOOT > 2.0.CO;2

Suarez MJ, Schopf PS. 1988. A Delayed Action Oscillator for ENSO. J. Atmos. Sci. 45: 3283-3287. DOI: 10.1175/15200469(1988)045<3283:ADAOFE > 2.0.CO;2

Trenberth KE, Hurrell J. 1994. Decadal atmosphere-ocean variations in the Pacific. Clim. Dyn. 9: 303-319. DOI: 10.1007/s003820050027.

Trenberth KE, Stepaniak DP. 2001. Indices of El Niño evolution. $J$. Climate 14: 1697-1701. DOI: $10.1175 / 1520-0442(2001) 014<1697$ : $\mathrm{LIOENO}>2.0 . \mathrm{CO} ; 2$

Troup AJ. 1965. The southern oscillation. Q. J. R. Meteorol. Soc. 91: 490-506. DOI: 10.1002/qj.49709139009.

Turner AG, Inness PM, Slingo JM. 2005. The role of the basic state in the ENSO-monsoon relationship and implications for predictability. Q. J. R. Meteorol. Soc. 131: 781-804. DOI: 10.1256/qj.04.70.

Turner AG, Inness PM, Slingo JM. 2007. The effect of doubled $\mathrm{CO}_{2}$ and model basic state biases on the monsoon-ENSO system. Part I: Mean response and interannual variability. Q. J. R. Meteorol. Soc. In press. DOI: $10.1002 /$ qj82.

Urban FE, Cole JE, Overpeck JT. 2000. Influence of mean climate change on climate variability from a 155-year tropical Pacific coral record. Nature 407: 989-993. DOI:10.1038/35 039597.

Wang B, An SI. 2002. A mechanism for decadal changes of ENSO behaviour: roles of background wind changes. Clim. Dyn. 18: 475-486. DOI: 10.1007/s00382-001-0189-5.

Wang B, Barcilon A, Fang Z. 1999. Stochastic Dynamics of El NiñoSouthern Oscillation. J. Atmos. Sci. 56: 5-23. DOI: 10.1175/15200469(1999)056<0005:SDOENO > 2.0.CO;2 
Webster PJ, Yang S. 1992. Monsoon and ENSO: Selectively interactive systems. O. J. R. Meteorol. Soc. 118: 877-926. DOI 10.1002/qj.49711850705.

Wu R, Kirtman BP. 2004. The Tropospheric Biennial Oscillation of the Monsoon-ENSO System in an Interactive Ensemble Coupled GCM. J. Climate 17: 1623-1640. DOI: 10.1175/15200442(2004)017<1623:TTBOOT>2.0.CO;2.

Yasunari T. 1991. The Monsoon Year - A New Concept of the Climatic Year in the Tropics. Bull. Am. Meteorol. Soc. 72: 1331-1338. DOI: 10.1175/1520-0477(1991)072<1331:TMYNCO >2.0.CO;2.
Zebiak SE, Cane MA. 1987. A Model El Niño-Southern Oscillation. Mon. Weather Rev. 115: 2262-2278. DOI: 10.1175/15200493(1987) $115<2262$ :AMENO > 2.0.CO;2.

Zelle H, van Oldenborgh GJ, Dijkstra H. 2005. El Niño and Greenhouse Warming: Results from Ensemble Simulations with the NCAR CCSM. J. Climate 18: 4669-4683. DOI: 10.1175/JCLI3574.1. 